\title{
Oceanic sources, sinks, and transport of atmospheric $\mathrm{CO}_{2}$
}

\author{
Nicolas Gruber, ${ }^{1}$ Manuel Gloor, ${ }^{2}$ Sara E. Mikaloff Fletcher, ${ }^{3}$ Scott C. Doney, ${ }^{4}$ \\ Stephanie Dutkiewicz, ${ }^{5}$ Michael J. Follows, ${ }^{5}$ Markus Gerber, ${ }^{6}$ Andrew R. Jacobson, ${ }^{7}$ \\ Fortunat Joos, ${ }^{6,8}$ Keith Lindsay, ${ }^{9}$ Dimitris Menemenlis, ${ }^{10}$ Anne Mouchet, ${ }^{11}$ \\ Simon A. Müller, ${ }^{6,13}$ Jorge L. Sarmiento, ${ }^{3}$ and Taro Takahashi ${ }^{12}$ \\ Received 27 August 2008; accepted 21 October 2008; published 18 February 2009.
}

[1] We synthesize estimates of the contemporary net air-sea $\mathrm{CO}_{2}$ flux on the basis of an inversion of interior ocean carbon observations using a suite of 10 ocean general circulation models (Mikaloff Fletcher et al., 2006, 2007) and compare them to estimates based on a new climatology of the air-sea difference of the partial pressure of $\mathrm{CO}_{2}$ $\left(p \mathrm{CO}_{2}\right)$ (Takahashi et al., 2008). These two independent flux estimates reveal a consistent description of the regional distribution of annual mean sources and sinks of atmospheric $\mathrm{CO}_{2}$ for the decade of the 1990s and the early 2000s with differences at the regional level of generally less than $0.1 \mathrm{Pg} \mathrm{C} \mathrm{a}^{-1}$. This distribution is characterized by outgassing in the tropics, uptake in midlatitudes, and comparatively small fluxes in the high latitudes. Both estimates point toward a small $\left(\sim-0.3 \mathrm{Pg} \mathrm{C} \mathrm{a}^{-1}\right)$ contemporary $\mathrm{CO}_{2}$ sink in the Southern Ocean (south of $44^{\circ} \mathrm{S}$ ), a result of the near cancellation between a substantial outgassing of natural $\mathrm{CO}_{2}$ and a strong uptake of anthropogenic $\mathrm{CO}_{2}$. A notable exception in the generally good agreement between the two estimates exists within the Southern Ocean: the ocean inversion suggests a relatively uniform uptake, while the $p \mathrm{CO}_{2}$-based estimate suggests strong uptake in the region between $58^{\circ} \mathrm{S}$ and $44^{\circ} \mathrm{S}$, and a source in the region south of $58^{\circ} \mathrm{S}$. Globally and for a nominal period between 1995 and 2000, the contemporary net air-sea flux of $\mathrm{CO}_{2}$ is estimated to be $-1.7 \pm 0.4 \mathrm{Pg} \mathrm{Ca}^{-1}$ (inversion) and $-1.4 \pm 0.7 \mathrm{Pg} \mathrm{C} \mathrm{a}^{-1}\left(\mathrm{CO}_{2}\right.$-climatology), respectively, consisting of an outgassing flux of river-derived carbon of $\sim+0.5 \mathrm{Pg} \mathrm{C} \mathrm{a}^{-1}$, and an uptake flux of anthropogenic carbon of $-2.2 \pm 0.3 \mathrm{Pg} \mathrm{C} \mathrm{a}^{-1}$ (inversion) and $-1.9 \pm 0.7 \mathrm{Pg} \mathrm{C} \mathrm{a}^{-1}$ ( $p \mathrm{CO}_{2}$-climatology). The two flux estimates also imply a consistent description of the contemporary meridional transport of carbon with southward ocean transport throughout most of the Atlantic basin, and strong equatorward convergence in the Indo-Pacific basins. Both transport estimates suggest a small hemispheric asymmetry with a southward transport of between -0.2 and $-0.3 \mathrm{Pg} \mathrm{C} \mathrm{a}^{-1}$ across the equator. While the convergence of these two independent estimates is encouraging and suggests that it is now possible to provide relatively tight constraints for the net air-sea $\mathrm{CO}_{2}$ fluxes at the regional basis, both studies are limited by their lack of consideration of long-term changes in the ocean carbon cycle, such as the recent possible stalling in the expected growth of the Southern Ocean carbon sink.

Citation: Gruber, N., et al. (2009), Oceanic sources, sinks, and transport of atmospheric $\mathrm{CO}_{2}$, Global Biogeochem. Cycles, 23, GB1005, doi:10.1029/2008GB003349.

\footnotetext{
${ }^{1}$ Environmental Physics, Institute of Biogeochemistry and Pollutant Dynamics, ETH Zürich, Zürich, Switzerland.

${ }^{2}$ Institutes of Earth and Biosphere and Earth, Energy and Environment and School of Geography, University of Leeds, Leeds, UK.

${ }^{3}$ Program in Atmospheric and Oceanic Sciences, Princeton University, Princeton, New Jersey, USA.

${ }^{4}$ Marine Chemistry and Geochemistry, Woods Hole Oceanographic Institution, Woods Hole, Massachusetts, USA.

${ }^{5}$ Department of Earth, Atmosphere, and Planetary Sciences, Massachusetts Institute of Technology, Cambridge, Massachusetts, USA.
}

Copyright 2009 by the American Geophysical Union. 0886-6236/09/2008GB003349

\footnotetext{
${ }^{6}$ Climate and Environmental Physics, Physics Institute, University of Bern, Bern, Switzerland.

${ }^{7}$ NOAA Earth System Research Laboratory, Global Monitoring Division, Boulder, Colorado, USA.

${ }^{8}$ Oeschger Centre for Climate Change Research, University of Bern, Bern, Switzerland.

${ }^{9}$ Climate and Global Dynamics, National Center for Atmospheric Research, Boulder, Colorado, USA.

${ }^{10} \mathrm{Jet}$ Propulsion Laboratory, California Institute of Technology, Pasadena, California, USA.

${ }^{11}$ Astrophysics and Geophysics Institute, University of Liege, Liege, Belgium.

${ }^{12}$ Lamont-Doherty Earth Observatory of Columbia University, Palisades, New York, USA.

${ }^{13}$ Now at Department of Earth and Environmental Sciences, Open University, Milton Keynes, UK.
} 


\section{Introduction}

[2] The exchange of carbon dioxide $\left(\mathrm{CO}_{2}\right)$ between the atmosphere and ocean is a critical process of the global carbon cycle and an important determinant of the future of the Earth system [Fung et al., 2005; Friedlingstein et al., 2006; Denman et al., 2007]. From 1800 until 1994, the ocean removed about $118 \pm 19 \mathrm{Pg} \mathrm{C}\left(1 \mathrm{Pg}=10^{15} \mathrm{~g}\right)$ from the atmosphere [Sabine et al., 2004]. This is equivalent to about $50 \%$ of the $\mathrm{CO}_{2}$ emitted into the atmosphere from the burning of fossil fuels or about $30 \%$ of the total anthropogenic $\mathrm{CO}_{2}$ emissions, which additionally include emissions from land use change and cement production [Houghton, 2003; Marland et al., 2006]. With this removal of anthropogenic $\mathrm{CO}_{2}$, the ocean constitutes the only net sink over the last 200 years, as the terrestrial biosphere is most likely a net source when integrated over this period [Sabine et al., 2004]. While the current sink strengths of the ocean and the land biosphere are similar [Sarmiento and Gruber, 2002; Manning and Keeling, 2006; Bender et al., 2005], model projections suggest that the land sink may decrease during this century or, perhaps, even turn into a source [Cox et al., 2000; Friedlingstein et al., 2006]. In contrast, the oceanic sink for atmospheric $\mathrm{CO}_{2}$ will likely continue to grow [Orr et al., 2001], highlighting the crucial role of the ocean as the ultimate sink for anthropogenic $\mathrm{CO}_{2}$. However, quantitative estimates of the oceanic sink strength and its regional distribution have remained uncertain, particularly for key regions such as the Southern Ocean [Caldeira and Duffy, 2000; Orr et al., 2001; Watson and Orr, 2003; Roy et al., 2003].

[3] A fundamental challenge is that the contemporary exchange flux of $\mathrm{CO}_{2}$ across the air-sea interface consists of a natural $\mathrm{CO}_{2}$ flux component, i.e., a $\mathrm{CO}_{2}$ flux that already existed in preindustrial times and is assumed to have changed little since, and an anthropogenic $\mathrm{CO}_{2}$ flux component that is driven by the anthropogenic perturbation in atmospheric $\mathrm{CO}_{2}$. The fluxes of both anthropogenic and natural $\mathrm{CO}_{2}$ are expected to change considerably in the future in response to continually rising atmospheric $\mathrm{CO}_{2}$ and global climate change [Sarmiento et al., 1998; Joos et al., 1999b; Matear and Hirst, 1999; Plattner et al., 2001; Gruber et al., 2004; Yoshikawa et al., 2008]. Therefore, in order to predict the future of the oceanic carbon sink and consequently the future evolution of atmospheric $\mathrm{CO}_{2}$, we need a quantitative estimate of the current sources and sinks for atmospheric $\mathrm{CO}_{2}$, as well as a mechanistic understanding of both components of the $\mathrm{CO}_{2}$ flux.

[4] Until recently, the ability to separately estimate the natural and anthropogenic $\mathrm{CO}_{2}$ flux components from observations was limited to the very indirect approach of computing the horizontal flux divergence of the oceanic transport of the respective carbon component [e.g., Holfort et al., 1998]. A more direct and often used approach, albeit without ability to separate the net flux into its two components, is the measurement of the air-sea difference of the partial pressure of $\mathrm{CO}_{2}\left(p \mathrm{CO}_{2}\right)$, which when combined with bulk gas exchange parameterizations yields an estimate of the net flux [Takahashi et al., 1997, 1999, 2002, 2008]. Another method to estimate net air-sea fluxes is the inversion of atmospheric $\mathrm{CO}_{2}$ observations [Bolin and Keeling, 1963; Enting and Mansbridge, 1989; Keeling et al., 1989; Tans et al., 1990;
Gurney et al., 2002, 2004; Baker et al., 2006]. The air-sea $\mathrm{CO}_{2}$ flux estimates obtained by all these approaches have remained uncertain owing to a combination of methodological uncertainties (e.g., uncertainty in the parameters for the bulk parameterization [Wanninkhof, 1992; Krakauer et al., 2006; Sweeney et al., 2007; Naegler et al., 2006]), uncertain atmospheric transports [Gurney et al., 2004], and insufficient data coverage [Gloor et al., 2000; Takahashi et al., 2002].

[5] A region of particularly large discrepancies between different flux estimates is the Southern Ocean, which we define here as the oceanic region south of $44^{\circ} \mathrm{S}$, with some older estimates indicating a very large uptake flux (order of $1 \mathrm{Pg} \mathrm{C} \mathrm{a}^{-1}$ and higher [Takahashi et al., 1997, 1999]) and others pointing toward a much lower uptake [Roy et al., 2003; McNeil et al., 2007]. This represents a critical gap in our understanding of the ocean carbon cycle, because this region appears to react very sensitively to climate variability and change [Wetzel et al., 2005; Le Quéré et al., 2007; Lovenduski et al., 2007, 2008; Lenton and Matear, 2007; Verdy et al., 2007], and because simulations indicate that the Southern Ocean likely will dominate the ocean's $\mathrm{CO}_{2}$ flux response during this century [Sarmiento et al., 1998; Orr et al., 2001].

[6] We synthesize here the results from a recently developed ocean inversion method [Gloor et al., 2003; Mikaloff Fletcher et al., 2006, 2007], which provides air-sea $\mathrm{CO}_{2}$ flux estimates that are based on inorganic carbon observations from the ocean interior, and are therefore entirely independent from estimates based on observations of the air-sea $p \mathrm{CO}_{2}$ difference or those based on atmospheric $\mathrm{CO}_{2}$. An added benefit is that the ocean inversion separately estimates the air-sea fluxes of natural and anthropogenic $\mathrm{CO}_{2}$, which when added together with an estimate of the outgassing of river derived carbon, give an estimate of the contemporary net air-sea flux of $\mathrm{CO}_{2}$. The anthropogenic $\mathrm{CO}_{2}$ flux results we use here have been presented and discussed by Mikaloff Fletcher et al. [2006], while in 2007 these authors summarized and discussed the natural $\mathrm{CO}_{2}$ flux results. This paper focuses on the contemporary air-sea $\mathrm{CO}_{2}$ flux results and compares them with the most recent flux estimates of Takahashi et al. [2008], which are based on an updated and greatly expanded analysis of surface ocean $p \mathrm{CO}_{2}$ observations. Moreover, we also compare our estimates with those derived from the inversion of atmospheric $\mathrm{CO}_{2}$ and from model studies. Finally, we provide and discuss estimates of the contemporary net transport of carbon implied by the inverse fluxes, and compare them to new estimates computed from the $p \mathrm{CO}_{2}$-based air-sea flux estimates taking into consideration the oceanic storage of anthropogenic carbon and fluxes of river-derived carbon.

[7] The ocean inverse flux results presented here are quantitatively similar to those reported by Jacobson et al. [2007b] on the basis of a joint atmosphere-ocean inversion. This is because the oceanic constraints in such a joint inversion are much stronger than the atmospheric ones, resulting in only small shifts from an ocean-only inversion. Relative to Jacobson et al. [2007b], the fluxes reported here are based on a larger and more diverse set of ocean general circulation models (OGCM), providing an improved assessment of the errors stemming from the possible biases in ocean transport. An additional improvement is that we resolve the spatial 
distribution of the fluxes at a substantially higher resolution; that is, we report and discuss results for 23 oceanic regions instead of just 11. Finally, we compare our estimates here with a broader and newer set of air-sea flux estimates, including the new $p \mathrm{CO}_{2}$-based estimates of Takahashi et al. [2008] and the new atmospheric inversion estimates of Baker et al. [2006].

[8] We will demonstrate that the ocean inverse estimates together with the new $p \mathrm{CO}_{2}$-based estimates provide an unprecedentedly consistent and precise depiction of the global distribution of the long-term annual mean sources and sinks of atmospheric $\mathrm{CO}_{2}$, with regional uncertainties of generally less than $0.1 \mathrm{Pg} \mathrm{C} \mathrm{a}^{-1}$. In particular, we show that these two estimates indicate a small net uptake flux of $\mathrm{CO}_{2}$ in the Southern Ocean, with a magnitude that is substantially smaller than previous estimates. An important caveat, however, is that both these estimates represent a long-term mean view of air-sea $\mathrm{CO}_{2}$ fluxes, and therefore cannot capture recent changes in these fluxes, such as those reported for the Southern Ocean [Le Quéré et al., 2007; Lovenduski et al., 2008], the North Atlantic [Schuster and Watson, 2007], the tropical Pacific [Takahashi et al., 2003; Feely et al., 2006], or the North Pacific [Keeling et al., 2004; Takahashi et al., 2006].

\section{Data and Methods}

[9] We provide here an abbreviated description of the ocean inversion method, and focus on how we assessed the errors. The reader interested in more details is referred to the underlying publications by Mikaloff Fletcher et al. [2006] and Mikaloff Fletcher et al. [2007] and their respective online auxiliary materials. ${ }^{1}$ A brief summary is also provided for the $p \mathrm{CO}_{2}$-based fluxes of Takahashi et al. [2008], particularly with regard to our estimation of the associated errors. Finally, we describe our methods to estimate the contemporary oceanic transport of carbon, in particular how we can combine the $p \mathrm{CO}_{2}$-based fluxes with the oceanic inventory of anthropogenic $\mathrm{CO}_{2}$ to arrive at a second, independent estimate of this transport.

\subsection{Ocean Inversion}

[10] The ocean inversion method is based on the premise that the ocean interior distribution of a soluble gas directly reflects the exchange of this gas across the air-sea interface, provided that it has no sources or sinks in the interior. Therefore, if ocean transport and mixing can be reversed, then regionally resolved air-sea fluxes of this gas can be inferred from ocean interior data by applying this "inverse" transport to the data [Gloor et al., 2001, 2003; Gruber et al., 2001]. In our case, this "inverse" transport is determined by releasing passive dye tracers at the surface of 30 prescribed regions in an Ocean General Circulation Model (OGCM). The model is integrated forward in time, resulting in the spreading of the dye tracers from the surface into the ocean's interior. The dye tracers are then sampled at locations and times corresponding to the space-time distribution of the observations. Because of

${ }^{1}$ Auxiliary materials are available in the HTML. doi:10.1029/ 2008GB003349 their very different atmospheric histories, separate dye tracer simulations are undertaken for natural and for anthropogenic $\mathrm{CO}_{2}$ [Gloor et al., 2003; Mikaloff Fletcher et al., 2006, 2007]. In the final inversion step, the sampled dye tracers, often referred to as basis functions, are combined linearly such that they match a set of observations most closely. The final airsea flux estimates are then obtained by multiplying the scaling factors with the amount of dye tracer released in each region to simulate the basis functions.

[11] The anthropogenic $\mathrm{CO}_{2}$ inversions used basis functions that were constructed by letting the source strength of the dyes to increase in line with the rise in atmospheric $\mathrm{CO}_{2}$ [Mikaloff Fletcher et al., 2006]. The model simulated basis functions were then sampled at the time and location for which data-based estimates of anthropogenic $\mathrm{CO}_{2}\left(C_{\text {ant }}\right)$ on the basis of the $\Delta C^{*}$ method [Gruber et al., 1996] are available. The natural $\mathrm{CO}_{2}$ inversions used basis functions that were created by keeping the source strength of the dyes constant through time, resulting, after several thousand years of integration, in basis functions that have a constant spatial pattern [Mikaloff Fletcher et al., 2007]. Those basis functions were then also sampled at the locations, for which data-based estimates of the gas-exchange component of dissolved inorganic carbon, i.e., $\Delta C_{\text {gas ex }}$, are available. The conservative tracer $\Delta C_{\text {gas ex }}$ was estimated from observations of dissolved inorganic carbon $(D I C)$, data-based estimates of $C_{\text {ant }}$, and several other tracers following the formulation of Gruber and Sarmiento [2002]. The GLODAP database [Key et al., 2004] was used as data source for both $C_{\text {ant }}$ and $\Delta C_{\text {gas ex }}$.

[12] Owing to a combination of data limitation and signal dispersion, we found that the inversion cannot reliably resolve the partitioning of the air-sea fluxes into all 30 regions. We addressed this limitation by combining, after the inversion, those regions whose partitioning is ill constrained. We identified these regions on the basis of an analysis of the matrix of region-region flux covariances [Mikaloff Fletcher et al., 2007]. This results in our reporting flux estimates for 23 regions.

\subsection{Error Assessment of Ocean Inverse Fluxes}

[13] For the ocean inversion, two sources of errors need to be considered: First, the uncertainties (random errors) and potential biases (systematic errors) associated with the data, and second, the potential biases in ocean transport. As the inversion makes use of a very large number of observations (more than 60,000), the impact of the random errors in the data turns out to be negligible. We therefore focus on the impact of the potential biases only.

[14] Matsumoto and Gruber [2005] reviewed and assessed the systematic errors associated with the $\Delta C^{*}$-derived estimates of $C_{\text {ant }}$ in detail and concluded that many of the potential biases tend to cancel, so that the distribution of $C_{\text {ant }}$ tends to be relatively robust. They identified, however, a tendency for $C_{\text {ant }}$ to be overestimated in the upper ocean and to be underestimated in the deeper ocean, with a possible overestimation of the global inventory of about $7 \%$. Mikaloff Fletcher et al. [2006] investigated the impact of these uncertainties and biases on the inverse estimates of the airsea fluxes of anthropogenic $\mathrm{CO}_{2}$ and demonstrated that the impact of the possible vertical distribution error of $C_{\text {ant }}$ is 
small but that any change in the global inventory will lead to a nearly equal relative change in the global uptake flux of anthropogenic $\mathrm{CO}_{2}$. Hence, a possible $7 \%$ reduction of the global inventory of anthropogenic $\mathrm{CO}_{2}$ will cause a nearly $7 \%$ reduction in the global uptake flux of anthropogenic $\mathrm{CO}_{2}$ in our inversion. Without a careful revaluation of the global inventory of anthropogenic $\mathrm{CO}_{2}$, it is premature, however, to adjust our flux estimate.

[15] The main source of systematic error in $\Delta C_{\text {gas ex }}$ is a possible bias in the carbon-to-phosphorus stoichiometric ratio, $r_{C: P}$, used to remove from $D I C$ the contribution of organic matter formation and decomposition. Mikaloff Fletcher et al. [2007] investigated the impact of this uncertainty, as well as that caused by uncertainty of $C_{\text {ant }}$, on the inferred estimates of the air-sea flux of natural $\mathrm{CO}_{2}$ and showed that the resulting differences in the estimated air-sea fluxes of natural $\mathrm{CO}_{2}$ are generally smaller than those arising from the use of the different OGCMs.

[16] In order to account for the error in ocean transport stemming from potential biases in the employed OGCMs, we use dye tracer simulations from a suite of 10 OGCMs, which span nearly the entire range of model behavior exhibited by the current generation of global-scale OGCMs used to model ocean biogeochemical processes [Matsumoto et al., 2004; Doney et al., 2004]. These dye-tracer simulations were undertaken by six different modeling groups: Princeton (PRINCE), Massachusetts Institute of Technology (MIT), Bern-Switzerland (Bern3D), Jet Propulsion Laboratory (ECCO), National Center for Atmospheric Research (NCAR), and University of Liège-Belgium (UL) (described in detail by Mikaloff Fletcher et al. [2006]). Princeton provided results from five different configurations of their model [Gnanadesikan et al., 2002, 2004]. The use of this large range of models permits a much improved assessment of model transport uncertainties compared to Gloor et al. [2003], who used only three configurations of the same OGCM, and Jacobson et al. [2007a, 2007b], who used only the Princeton suite of model configurations (albeit with different dye flux pattern within each region). The inverse estimates from the different models were aggregated to a mean flux, whereby each model was weighted according to a skill score [Taylor, 2001] to account for the substantial differences in the model's ability to correctly simulate the oceanic distribution of passive tracers. For the natural $\mathrm{CO}_{2}$ inversions, we used a skill score based on natural radiocarbon, while for the anthropogenic $\mathrm{CO}_{2}$ inversions, we used a score based on chlorofluorocarbons (CFC). In both cases, observations were taken from GLODAP [Key et al., 2004].

[17] Despite large differences in model architecture, setup, and forcing, the employed OGCMs share certain shortcomings. This means that the weighted mean fluxes cannot necessarily be viewed as unbiased estimates. The most important shared shortcoming of all employed OGCMs is their coarse resolution, which requires the parameterization of mesoscale processes. Furthermore, all of the models use $z$ coordinates as their vertical discretization, leading to potential problems when flow over steep topography has to be resolved, for example. Common problems in the resulting ocean circulation fields are (1) a too southerly formation region for North Atlantic Deep Water (NADW), which results in a too shallow southward flowing of NADW, (2) equatorial current systems that are often only partially resolved, (3) a strong sensitivity of the modeled circulation fields to small changes in the parameters for subgrid-scale parameterization, and (4) problems with the correct formation of intermediate and deep waters in the Southern Ocean. Finally, all models were forced with a seasonally resolved climatology based on data from the second half of the 20th century. As a result, none of these models include the potential effects of climate variability and change on ocean circulation.

\subsection{Air-Sea Fluxes of River-Derived Carbon}

[18] The steady state outgassing of natural $\mathrm{CO}_{2}$ caused by the input of organic and inorganic carbon by rivers [Sarmiento and Sundquist, 1992] must be properly considered in order to be able to compare our inverse estimates of the air-sea $\mathrm{CO}_{2}$ fluxes with those based on the air-sea difference of $p \mathrm{CO}_{2}$. It appears that our inversion of $\Delta C_{\text {gas ex }}$ only partially resolves this steady state outgassing flux of natural $\mathrm{CO}_{2}$. This conclusion is based on our finding of a global near-zero flux of natural $\mathrm{CO}_{2}$ in the absence of our imposing such a constraint. We interpret this as evidence that our natural $\mathrm{CO}_{2}$ flux estimates are based on a nearly "perfect" inversion; that is, we assume that the $\Delta C_{\text {gas ex }}$ data reflect both the addition of inorganic carbon from rivers (either directly as $D I C$ or by the remineralization of organic carbon), which the inversion erroneously interprets as an uptake of $\mathrm{CO}_{2}$ from the atmosphere, as well as the loss of inorganic carbon due to the outgassing of this riverine $\mathrm{CO}_{2}$, which the inversion interprets correctly as an air-sea flux. This requires an adjustment of the "raw" natural $\mathrm{CO}_{2}$ flux estimates to obtain a correct estimate of the global net air-sea flux of $\mathrm{CO}_{2}$ (see Text S1 for a more detailed discussion).

[19] Following Jacobson et al. [2007a], we adopt a global total outgassing of $+0.45 \mathrm{Pg} \mathrm{C} \mathrm{a}^{-1}$, which is partitioned among all regions using spatially resolved estimates of the carbon input by rivers [Ludwig et al., 1996]. The magnitude of this river outgassing-induced adjustment and its spatial allocation is very uncertain, resulting in our assigning a $\pm 50 \%$ uncertainty to these flux adjustments.

\subsection{Air-Sea Fluxes Derived From $\mathrm{pCO}_{2}$-Data}

[20] Relative to the $p \mathrm{CO}_{2}$ climatology described by Takahashi et al. [2002], the new climatology by Takahashi et al. [2008] includes several improvements: First, the total number of $p \mathrm{CO}_{2}$ observations was tripled to nearly 3 million, with the largest improvement occurring in the southern hemisphere (especially south of $50^{\circ} \mathrm{S}$ ). Second, in the high latitudes, the assumptions required to correct the oceanic $p \mathrm{CO}_{2}$ observations stemming from several decades to a single reference year (year 2000) were substantially altered. In previous climatologies, the $p \mathrm{CO}_{2}$ in the high latitudes was assumed to have a growth rate that is much smaller than that of the rest of the surface ocean, which was assumed to follow the atmospheric $p \mathrm{CO}_{2}$ growth rate. In contrast, Takahashi et al. [2008] assumed for the new climatology that all oceanic regions have the same rate of increase of $1.5 \mu \mathrm{atm} \mathrm{a}^{-1}$. This change contributed to the significant reduction in the magnitude of the sea-air $p \mathrm{CO}_{2}$ 
differences in comparison to Takahashi et al. [2002] and hence the magnitude of the $\mathrm{CO}_{2}$ sink flux over the Southern Ocean. Third, a new parameterization was used to estimate oceanic $p \mathrm{CO}_{2}$ during wintertime in regions with high seaice concentrations.

[21] Takahashi et al. [2008] computed the net air-sea flux from the monthly $p \mathrm{CO}_{2}$ climatology using climatological mean monthly values for wind speed $(10$ meters above surface) and ice cover percentage estimated on the basis of the NCEP Reanalysis 2 data. A square dependence of the gas transfer velocity on the windspeed was employed for the central flux estimate, but with a coefficient $(0.26)$ that is considerably smaller than that previously used in order to account for the emerging evidence of a smaller oceanic inventory of bomb radiocarbon than previously assumed [Naegler et al., 2006; Sweeney et al., 2007; Peacock, 2004; Müller et al., 2008].

[22] While Takahashi et al. [2008] did not provide regionally resolved uncertainties for their fluxes, they estimated an error of the global flux of about $\pm 50 \%$, with the largest contributions stemming from uncertainties in the gas transfer velocity and the annual rate of change of surface ocean $p \mathrm{CO}_{2}$ (determined over only $27 \%$ of the global oceans). In order to obtain regionally resolved estimates of the error associated with the $p \mathrm{CO}_{2}$-derived fluxes, we focus on the contribution of the gas transfer velocity, and recomputed the fluxes using 6 different gas-transfer velocity models: The linear windspeed dependent model of Krakauer et al. [2006] scaled to a global mean gas transfer velocity of $19 \mathrm{~cm} \mathrm{~h}^{-1}$, the squared windspeed dependent models of Wanninkhof [1992], of Nightingale et al. [2000], of Ho et al. [2006], and of Sweeney et al. [2007], and the cubic windspeed dependent model of Wanninkhof and McGillis [1999]. The (unweighted) standard deviation of the 6 resulting flux estimates was used as an uncertainty estimate. We recognize that not all 6 gas transfer velocity models can be viewed as equally well supported by independent data. In particular, there is mounting evidence that the cubic windspeed dependent model of Wanninkhof and McGillis [1999] is the least likely to be correct [Krakauer et al., 2006; Sweeney et al., 2007]. We nevertheless keep this gas transfer model in our set, not the least in order to reflect other errors in the $p \mathrm{CO}_{2}-$ based estimates. For most regions, our procedure resulted in a relative error estimate of between about 30 to $50 \%$, consistent with the estimated uncertainty of the globally integrated flux.

\subsection{Ocean Transport}

[23] The contemporary oceanic transport of carbon implied by the air-sea fluxes of the ocean inversion is calculated by first computing individually the implied oceanic transports of natural and anthropogenic carbon, and then adding the two. We thereby neglect the possible transport of river-derived carbon. This is in accordance with our assumption made above that nearly all carbon added by rivers is lost to the atmosphere in the same large-scale region where it was added, i.e., that there is very little long-range transport of river derived carbon. This assumption disagrees with the conclusions drawn by Aumont et al. [2001], who argued that a substantial fraction of the river derived carbon is transported great distances in the ocean before it is vented back to the atmosphere. However, the assumptions made in their standard scenario are at the upper bound of what is presently considered defensible about the fate of riverderived carbon in the ocean, both with regard to their choice of using a high fraction that escapes estuaries, as well as with regard to their selection of a very long lifetime (1000 years) of the river-derived dissolved organic carbon (DOC) (see discussion by Jacobson et al. [2007a]). Arguably, the current level of understanding of the fate of riverderived carbon is very low, so that neither assumption can be excluded at present.

[24] As the natural carbon cycle is assumed to be in steady state, the implied transport can be directly calculated by integrating, from the north to the south, the air-sea fluxes, taking into consideration the net transports of natural carbon across the Bering Strait $\left(0 \mathrm{Pg} \mathrm{C} \mathrm{a}^{-1}\right)$ and the Indonesian Throughflow $\left(0.10 \pm 0.02 \mathrm{Pg} \mathrm{C} \mathrm{a}^{-1}\right.$, positive northward). These throughflows were estimated on the basis of the model simulated mass transports and the observed concentration of $\Delta C_{\text {gas ex }}$. As a result, these estimates include only that component of $D I C$ that exchanges with the atmosphere. For details, the reader is referred to Mikaloff Fletcher et al. [2007]. For calculating the transport of anthropogenic $\mathrm{CO}_{2}$, the same procedure is adopted, except that a storage term (rate of change of inorganic carbon due to the accumulation of anthropogenic $\mathrm{CO}_{2}$ ) needs to be considered as well, i.e., the integral consists of the sum of the air-sea fluxes and the vertically integrated storage term. For the throughflows, a value of $0.007 \mathrm{Pg} \mathrm{C} \mathrm{a}^{-1}$ was used for the Bering Strait and $-0.19 \mathrm{Pg} \mathrm{C} \mathrm{a}^{-1}$ for the Indonesian Strait, also based on model transports and observational estimates of $C_{\text {ant }}$. For details regarding the transport of anthropogenic $\mathrm{CO}_{2}$, the reader is referred to Mikaloff Fletcher et al. [2006].

[25] A second, independent estimate of the contemporary ocean transport can be derived from the $p \mathrm{CO}_{2}$-based air-sea flux estimates, provided one can correct for the river input of carbon and its subsequent outgassing $\left(F_{\text {river }}\right)$, and one can estimate the storage term that arises in the ocean as a result of the uptake of anthropogenic $\mathrm{CO}_{2}$ (vertically integrated rate of change of $D I C$, i.e. $\left.\int(d D I C / d t) d z\right)$. We thus estimate the transport of carbon, $T(y)$, in meridional direction $(y)$ from the $p \mathrm{CO}_{2}$-derived air-sea flux estimate $\left(F_{s a}\right.$, positive upward) by the integral:

$$
T(y)=T\left(y_{0}\right)+\int_{y_{0}}^{y}\left(F_{\mathrm{sa}}-\int_{-H}^{0} \frac{d D I C}{d t} d z-F_{\text {river }}\right) d y,
$$

where $T\left(y_{0}\right)$ is the transport at the northern boundary, and where the integral is evaluated from the north to the south. We estimate the storage term from GLODAP's column inventory of anthropogenic $\mathrm{CO}_{2}, C_{\text {ant }}(t)$, [Key et al., 2004] taking advantage of the result that in a transient steady state [Gammon et al., 1982], the rate of change of a transient tracer is directly proportional to its total burden, especially when integrated vertically from the bottom of the ocean, $-H$, to the surface (see also Mikaloff Fletcher et al. [2006] and Tanhua et al. [2007]), i.e.,

$$
\int_{-H}^{0} \frac{d D I C}{d t} d z \approx \int_{-H}^{0} \frac{C_{\text {ant }}}{d t} d z \approx \gamma \cdot \int_{-H}^{0} C_{\text {ant }}(t) d z
$$


[26] The proportionality factor $\gamma$ can be determined from the ratio between the global rate of oceanic uptake of anthropogenic $\mathrm{CO}_{2}\left(1.9 \mathrm{Pg} \mathrm{C} \mathrm{a}{ }^{-1}\right)$ [Takahashi et al., 2008] and the global oceanic inventory of anthropogenic $\mathrm{CO}_{2}$ (118 Pg C) [Sabine et al., 2004], i.e., 1/62 $\mathrm{a}^{-1}$. This approximation works for $\mathrm{CO}_{2}$ as long as the change in the buffer factor resulting from ocean acidification remains small. This proportionality factor is expected to be spatially very uniform, as spatial variations in the buffer factor are already reflected in the variations in the anthropogenic $\mathrm{CO}_{2}$ column burden.

[27] For the river fluxes, $F_{\text {river, }}$, we assume, as above, that the river loop does not involve long-range transport in the ocean, and therefore directly use our previously estimated river-induced air-sea fluxes of $\mathrm{CO}_{2}$ (positive upward). Since the Arctic and the northern North Atlantic are not covered by GLODAP, the integral is only evaluated south of $62^{\circ} \mathrm{N}$, requiring the specification of a transport $T\left(y_{0}\right)$ at this boundary. We chose a value of $-0.06 \mathrm{Pg} \mathrm{C} \mathrm{a}^{-1}$ at $62^{\circ} \mathrm{N}$ in the North Atlantic on the basis of the ocean inverse transport estimates.

\section{Contemporary Air-Sea Fluxes}

\subsection{Large-Scale Distribution}

[28] The contemporary air-sea $\mathrm{CO}_{2}$ fluxes, aggregated to 10 large-scale regions for clarity, show the familiar annual mean pattern of outgassing of $\mathrm{CO}_{2}$ in the tropical regions and uptake of atmospheric $\mathrm{CO}_{2}$ nearly everywhere else (Figure 1a) (a listing of the estimated fluxes for all 23 regions and for a nominal year of 1995 is given in Table S1). The strongest outgassing is diagnosed in the tropical Pacific, where we find an outgassing of nearly $+0.4 \mathrm{Pg} \mathrm{C} \mathrm{a}^{-1}$. The temperate latitude regions in the different ocean basins contribute nearly equally to the oceanic sink for atmospheric $\mathrm{CO}_{2}$, with an uptake flux between $\sim-0.2$ and $\sim-0.5 \mathrm{Pg} \mathrm{C}$ $\mathrm{a}^{-1}$. The high-latitude regions, i.e., the North Atlantic and Arctic $\left(>49^{\circ} \mathrm{N}\right)$, and the Southern Ocean $\left(<44^{\circ} \mathrm{S}\right)$, are comparatively weak sink regions. At the hemispheric scale, we find that the southern hemisphere extra tropics $\left(<18^{\circ} \mathrm{S}\right)$ is the largest sink region, with an uptake of $-1.4 \pm 0.3 \mathrm{Pg} \mathrm{C} \mathrm{a}^{-1}$, mostly reflecting its large surface area. By contrast, the contemporary uptake flux of the northern hemisphere extra tropics $\left(>18^{\circ} \mathrm{N}\right)$ accounts for only $-0.9 \pm 0.1 \mathrm{Pg} \mathrm{C} \mathrm{a}^{-1}$ (Table S1). The total outgassing in the tropics $\left(18^{\circ} \mathrm{S}\right.$ to $\left.18^{\circ} \mathrm{N}\right)$ amounts to $+0.6 \pm 0.1 \mathrm{Pg} \mathrm{C}^{-1}$. This results in a global contemporary net uptake of $\mathrm{CO}_{2}$ of $-1.7 \pm 0.4 \mathrm{Pg} \mathrm{C} \mathrm{a}^{-1}$. As will be discussed below in more detail, this global integral consists of an anthropogenic $\mathrm{CO}_{2}$ uptake flux of $-2.2 \pm 0.3 \mathrm{Pg} \mathrm{C} \mathrm{a}^{-1}$ [Mikaloff Fletcher et al., 2006] (for a nominal year of 1995) and a net natural $\mathrm{CO}_{2}$ outgassing flux of $+0.5 \pm 0.2 \mathrm{Pg} \mathrm{Ca}^{-1}$, with the latter almost entirely driven by the outgassing of river derived $\mathrm{CO}_{2}$.

[29] The comparison of our inverse estimates of the contemporary air-sea $\mathrm{CO}_{2}$ flux with a selection of the most recent independent estimates reveals a relatively consistent pattern in the northern hemisphere, but larger differences in the southern hemisphere, particularly in the temperate South Pacific and in the Southern Ocean (Figure 1a). Included in this comparison are three fundamentally different types of flux estimates: The first is the $p \mathrm{CO}_{2}$ based estimate of
Takahashi et al. [2008], the second stems from forward simulation results by 13 ocean biogeochemistry models that participated in the 2 nd phase of the Ocean Carbon-cycle Model Intercomparison Project (OCMIP-2) [Watson and Orr, 2003; Najjar et al., 2007], and the third is based on an interannual inversion of atmospheric $\mathrm{CO}_{2}$ undertaken by the TransCom-3 intercomparison project [Baker et al., 2006] (the so-called level 3 inversion of TransCom). Since the latter two estimates involve models to a substantial degree, we first focus our discussion on the comparison with the most recent $p \mathrm{CO}_{2}$-based estimate of Takahashi et al. [2008].

\subsection{Regional Comparison}

[30] At this aggregated scale, our inverse estimates of the contemporary air-sea $\mathrm{CO}_{2}$ flux and the new $\mathrm{pCO}_{2}$-based estimate agree with each other to generally within better than $0.1 \mathrm{Pg} \mathrm{C} \mathrm{a}^{-1}$ (Figure 1a). The largest exception is the temperate South Pacific (ocean inversion regions 20-24), where the ocean inverse uptake estimate of $-0.46 \pm 0.11 \mathrm{Pg} \mathrm{C} \mathrm{a}^{-1}$ exceeds the $\mathrm{pCO}_{2}$ based flux by $0.18 \pm 0.15 \mathrm{Pg} \mathrm{C}^{-1}$. The temperate South Pacific is among the least sampled regions in terms of $p \mathrm{CO}_{2}$. Several $4 \times 5^{\circ}$ grid cells have no observations at all [see Takahashi et al., 2008, Figure 1], and about 15\% of all grid cells have observations for only a single month. The seasonal coverage is such that, on average, each grid cell has observations for only 5 out of the 12 months. As a result, a substantial amount of extrapolation had to be undertaken in order to create a $p \mathrm{CO}_{2}$ climatology that contains values for all grid cells and all months of the year. Since the $p \mathrm{CO}_{2}$ in the surrounding regions tends to be higher, it is conceivable that the resulting interpolated $p \mathrm{CO}_{2}$ fields are biased high, resulting in a $p \mathrm{CO}_{2}$-based flux estimate that is biased toward a smaller sink. The ocean inverse estimates may be biased as well, particularly since the inversion has some problems to separate the fluxes between the western temperate South Pacific (regions 20 and 22) and the subpolar South Pacific and South Indian (regions 25 and 30).

[31] The next exceptions are the northern North Atlantic/ Arctic (regions 1-2) and the temperate North Atlantic regions (regions 3-4). In the former region, the inverse uptake estimate is $0.15 \pm 0.14 \mathrm{Pg} \mathrm{C}^{-1}$ smaller than the $p \mathrm{CO}_{2}$-based flux estimate, whereas in the latter region, the inverse uptake estimate exceeds that on the basis of the $p \mathrm{CO}_{2}$ data by $0.12 \pm 0.12 \mathrm{Pg} \mathrm{C}^{-1}$; that is, the inversion puts the maximum of the North Atlantic uptake further south in comparison to what the $p \mathrm{CO}_{2}$ data indicate. Since the data coverage for the $p \mathrm{CO}_{2}$ climatology for this region is among the best worldwide, it is unlikely that the lack of data is responsible for this discrepancy. A more likely reason is the shared problem among all OGCMs employed here of having a tendency to produce NADW too far south, with little or no formation in the Nordic Seas, and with the southward flow of this water mass in the Atlantic occurring at too shallow depths [Doney et al., 2004]. In the inversion, this circulation bias tends to cause an erroneous southward shift in the region of uptake of both natural and anthropogenic $\mathrm{CO}_{2}$ in the North Atlantic [Mikaloff Fletcher et al., 2006, 2007], explaining why the inverse uptake flux of $\mathrm{CO}_{2}$ exceeds that based on $p \mathrm{CO}_{2}$ in the temperate North Atlantic and underestimates the uptake in the northern 


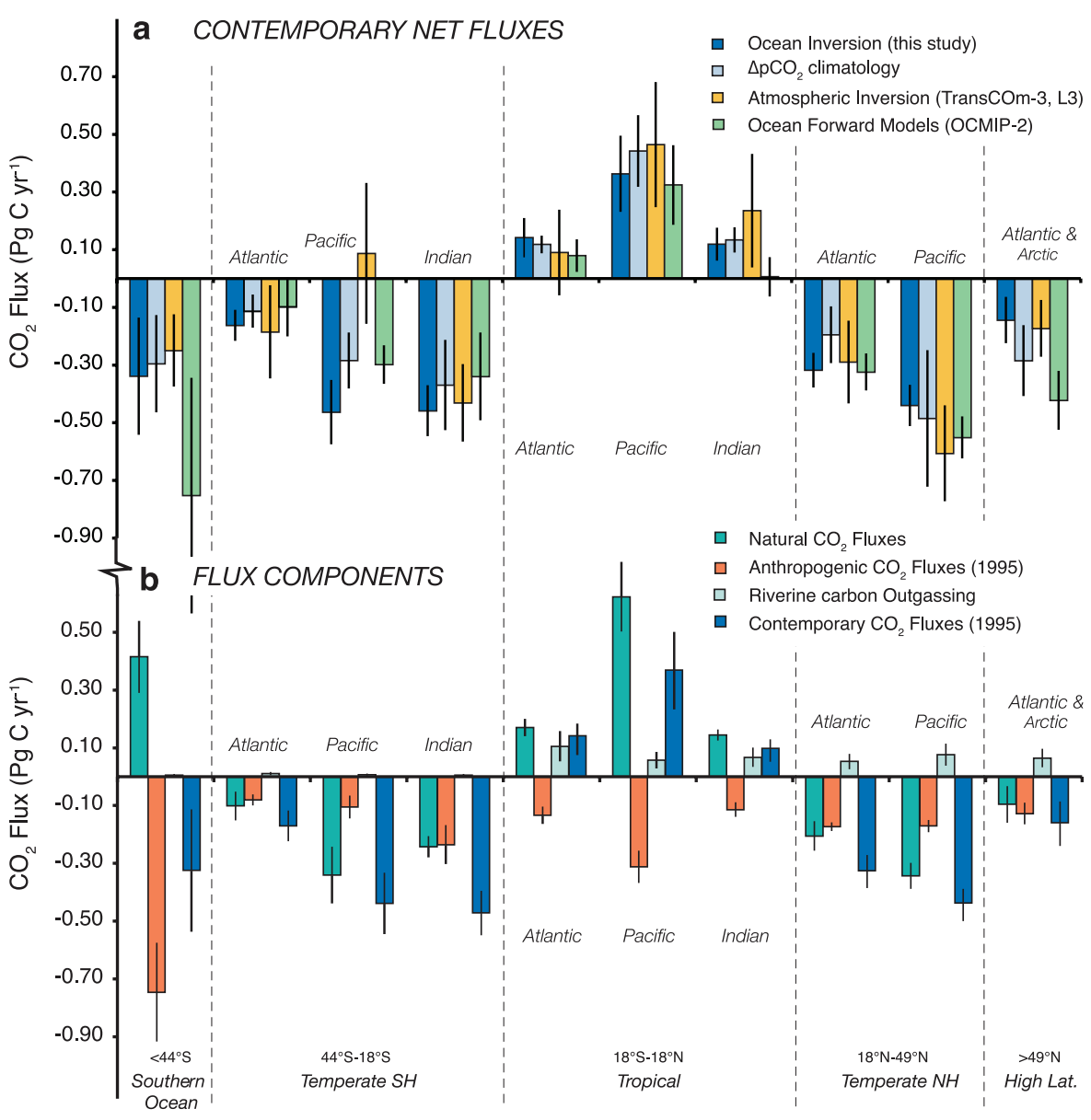

Figure 1. Air-sea $\mathrm{CO}_{2}$ fluxes for 10 regions, ordered by latitude and Ocean basin (positive: outgassing; negative: uptake). (a) Comparison of contemporary air-sea fluxes of $\mathrm{CO}_{2}$. Shown are the ocean inversion estimates (this study), the new $p \mathrm{CO}_{2}$-based estimates of Takahashi et al. [2008], the mean estimates based on results from the 13 ocean biogeochemistry models that participated in the second phase of the Ocean Carbon-cycle Model Intercomparison Project (OCMIP-2) [Watson and Orr, 2003], and the mean estimates from the TransCom-3 project based on the interannual (level 3) inversions of atmospheric $\mathrm{CO}_{2}$ [Baker et al., 2006]. The uncertainties for the OCMIP-2 estimates reflect the (unweighted) standard deviation across the 13 models, while the uncertainties for the TransCom estimates were obtained by quadrature of the within and between model errors reported by Baker et al. [2006]. (b) Weighted mean estimates of the natural, anthropogenic, river-induced, and contemporary air-sea fluxes of $\mathrm{CO}_{2}$ based on our ocean inversion [Mikaloff Fletcher et al., 2006, 2007]. The results are aggregated to 10 regions from the 23 regions solved for in the inversion for reasons of clarity. Error bars denote the cross-model weighted standard deviation of the mean. The anthropogenic and contemporary $\mathrm{CO}_{2}$ fluxes are for a nominal year of 1995 .

North Atlantic and in the Arctic. This interpretation is confirmed by the nearly negligible difference of $0.02 \mathrm{Pg} \mathrm{C} \mathrm{a}^{-1}$ when the sum of the fluxes from these two regions is compared.

[32] The generally good agreement at the aggregated level of 10 regions exists even when comparing the two flux estimates at the full 23 region resolution of the ocean inversion (Figure 2). With only two exceptions, the two flux estimates still agree with each other to within better than $0.10 \mathrm{Pg} \mathrm{C} \mathrm{a}^{-1}$. The standard deviation of the difference between the two estimates is $0.08 \mathrm{Pg} \mathrm{C} \mathrm{a}^{-1}$, only slightly larger than the estimated error for each method within each region, which amounts, on average, to $0.06 \mathrm{Pg} \mathrm{C} \mathrm{a}^{-1}$ for the inversion, and
$0.05 \mathrm{Pg} \mathrm{C} \mathrm{a}^{-1}$ for the $p \mathrm{CO}_{2}$ based estimates. Thus, for the most part, the two estimates are statistically indistinguishable. But there are notable exceptions.

[33] In the temperate South Pacific, this more detailed analysis reveals that the majority of the discrepancy identified above occurs in the western part, i.e., west of about $120^{\circ} \mathrm{W}$ (regions 20 and 22), since the net fluxes in the eastern part (regions 21 and 23-24) are small and differ little between the two estimates. Although the data coverage in the western region is somewhat better than that in the eastern region, the average grid cell in this region still contains observations for only 6 months out of 12, on average, requiring a substantial amount of interpolation in a region of high uptake fluxes. 


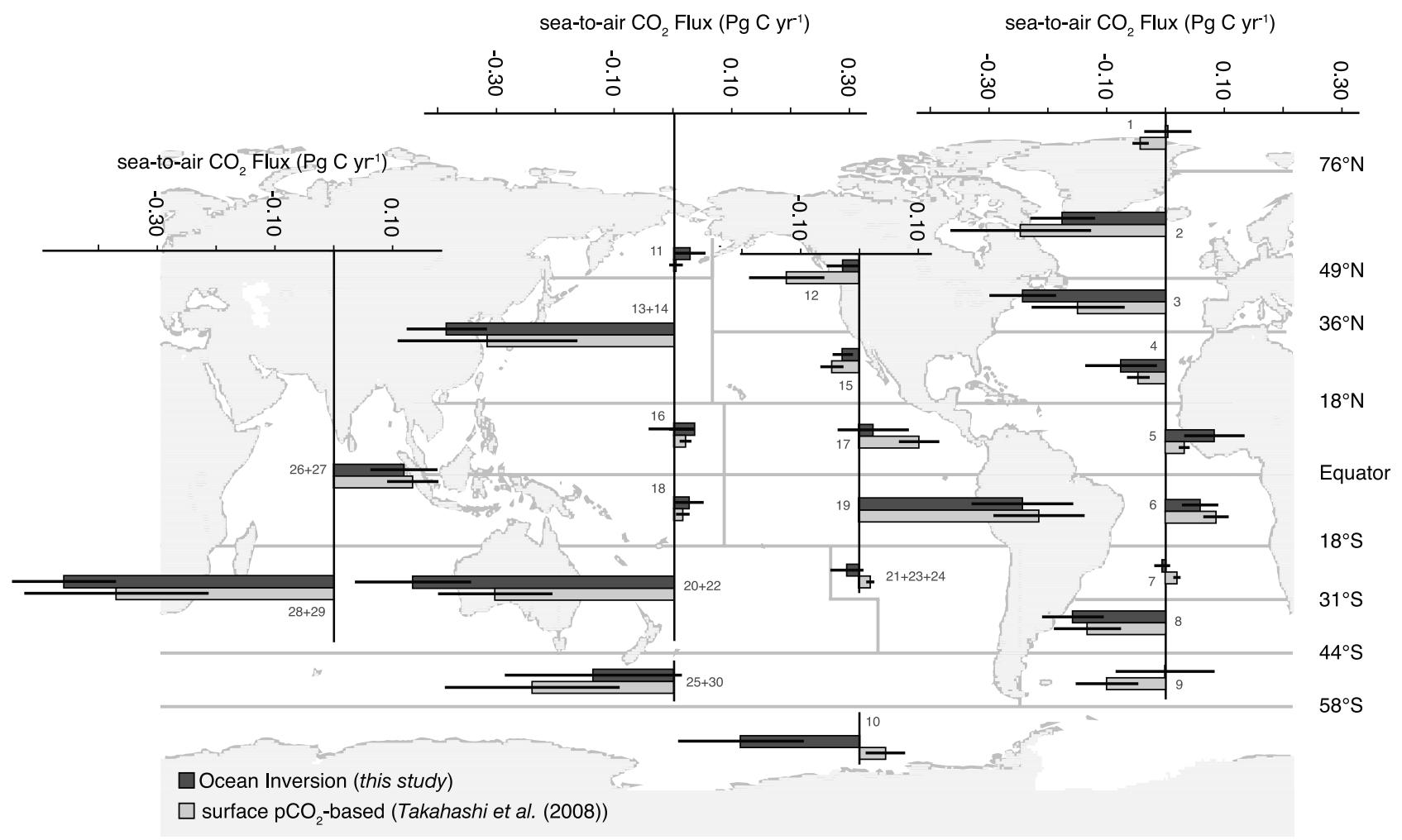

Figure 2. Comparison of the ocean inversion estimate of the contemporary sea-to-air $\mathrm{CO}_{2}$ flux with that based on the $\mathrm{pCO}_{2}$ climatology of Takahashi et al. [2008] for each of the 23 regions resolved by the ocean inversion. The zero-line crossing of each flux estimate indicates the region that this flux belongs to. Small gray numbers indicate the region number (see Table S1 for the region name). Positive fluxes indicate outgassing.

[34] In the North Atlantic, this more finely resolved depiction makes the southward shift of the maximum sink strength in the ocean inversion relative to the $p \mathrm{CO}_{2}$-based estimates even more evident. It shows that it is primarily the relative allocation of the North Atlantic sink between the midlatitude North Atlantic (region $3,36^{\circ} \mathrm{N}-49^{\circ} \mathrm{N}$ ) and the subpolar North Atlantic (region $2,49^{\circ} \mathrm{N}-76^{\circ} \mathrm{N}$ ) that causes the discrepancy, consistent with our interpretation that this mismatch is primarily caused by a common bias in the OGCMs, i.e., that the ocean inverse estimates are spatially biased.

[35] The higher-resolution estimates reveal also a slightly different regional attribution of the North Pacific sink. The inversion suggests a stronger zonal gradient in the fluxes with a stronger sink in the west, primarily in the western subtropical North Pacific (regions 13-14) and a weaker sink in the east (subpolar North East Pacific, region 12). In contrast, the $p \mathrm{CO}_{2}$-based estimate has a zonally more uniform distribution. The difference (inversion minus $p \mathrm{CO}_{2}$ climatology) amounts to $-0.07 \pm 0.17 \mathrm{Pg} \mathrm{C} \mathrm{a}^{-1}$ in the western subtropical North Pacific and to $0.10 \pm 0.07 \mathrm{Pg} \mathrm{C}^{-1}$ in the subpolar North East Pacific. Since the North Pacific also belongs to the well-sampled regions in the $p \mathrm{CO}_{2}$ climatology of Takahashi et al. [2008], it is unlikely that undersampling is causing this discrepancy. But the substantial decadal changes in the upper ocean carbon cycle in this region [Takahashi et al., 2006; Keeling et al., 2004] in connection with the temporal distribution of the $p \mathrm{CO}_{2}$ observations could have led to a temporal sampling bias in the $\mathrm{COO}_{2}$-based flux estimate, i.e., that in one region the fluxes represent primarily the conditions of one time period, while for the other region, the fluxes represent the conditions of another time period. However, the most likely explanation is a common bias in the OGCMs. Many global OGCMs have difficulties in simulating upper ocean physics correctly in this region [Gnanadesikan et al., 2002]. In particular, many models fail to reproduce the seasonal dynamics of upper ocean mixing, resulting in strong biases in mixed layer depth and other properties compared to observations [see, e.g., McKinley et al., 2006]. It is therefore conceivable that these circulation biases have caused the ocean inversion to allocate the sink further to the west in comparison to what the $p \mathrm{CO}_{2}$ climatology would suggest.

\subsection{Southern Ocean Fluxes}

[36] By far the largest discrepancy emerges in the Southern Ocean south of $44^{\circ} \mathrm{S}$. While the total sink strength south of $44^{\circ} \mathrm{S}$ agrees very well between the two estimates (inversion: $-0.34 \pm 0.20 \mathrm{Pg} \mathrm{C} \mathrm{a}^{-1} ; p \mathrm{CO}_{2}$ climatology: $-0.30 \pm 0.17 \mathrm{Pg}$ $\mathrm{C}^{-1}$ ), they suggest a strikingly different meridional distribution of the fluxes: The $p \mathrm{CO}_{2}$-based estimate puts all of the sink into the Subantarctic region between $44^{\circ} \mathrm{S}$ and $58^{\circ} \mathrm{S}$, and 
suggests that the region south of $58^{\circ} \mathrm{S}$, i.e., south of the Antarctic Polar Front (APF) is mostly a source to the atmosphere (see also Figures $4 \mathrm{a}$ and $4 \mathrm{~b}$ ). In contrast, the ocean inversion finds a more uniform distribution, in spite of the substantial changes in oceanographic processes across $58^{\circ} \mathrm{S}$. The Subantarctic region north of $58^{\circ} \mathrm{S}$ remains ice-free year round and is therefore also referred to as the Permanently Open Ocean Zone (POOZ), while much of the region south of $58^{\circ} \mathrm{S}$ experiences a seasonal cycle of sea-ice coverage, and is therefore referred to as the Seasonal Ice Zone (SIZ). The difference between the two flux estimates are larger than anywhere else: In the Subantarctic the difference (inversion minus $p \mathrm{CO}_{2}$ climatology) amounts to $0.20 \pm 0.24 \mathrm{Pg} \mathrm{C} \mathrm{a}^{-1}$, while the same difference is $-0.25 \pm 0.11 \mathrm{Pg} \mathrm{C} \mathrm{a}^{-1}$ in the Antarctic zone.

[37] Given these large regional differences within the Southern Ocean, is the absence of a large difference between the ocean inversion and the $p \mathrm{CO}_{2}$ climatology at the scale of the entire Southern Ocean south of $44^{\circ} \mathrm{S}$ robust? Or in other words, how much can we trust our finding of a relatively small Southern Ocean uptake of about $\sim-0.3 \mathrm{Pg} \mathrm{C} \mathrm{a}^{-1}$ ? Mikaloff Fletcher et al. [2006, 2007] and Jacobson et al. [2007b] undertook detailed studies to determine the errors of the inversely estimated fluxes resulting from uncertainties in the data, from assumptions associated with the determination of $\Delta C_{\text {gas ex }}$ and $C_{\text {ant }}$, and from errors in the OGCMs used to construct the basis functions. These studies concluded that the inversely estimated fluxes, once aggregated to the entire Southern Ocean are remarkably robust, and that the crossmodel uncertainties reported here are a good measure of the overall error of the flux estimates.

[38] This conclusion does not hold, however, at the regionally more resolved level. The inversion results from the individual models reveal, in part, a diametrically opposing pattern within the Southern Ocean (see Figure S1). Some models (e.g., one variant of the Princeton suite of models) estimate a very strong uptake in the Antarctic zone and outgassing in the Subantarctic, while others (e.g., the ECCO model) are nearly neutral in the Antarctic and suggest a strong uptake in the Subantarctic. A closer inspection reveals that much of this large variance in the flux estimates of the different models is due to how strongly the two component fluxes that make up the contemporary flux cancel each other, i.e., how much the outgassing of natural $\mathrm{CO}_{2}$ is compensated by the uptake of anthropogenic $\mathrm{CO}_{2}$ (see section 3.6 below for a more detailed discussion of the cancellation of these two component fluxes). This is related to how and where these models form intermediate, deep, and bottom waters in the Southern Ocean [Dutay et al., 2002]. Some models tend to form deep and bottom waters by open ocean convection, while others tend to form it exclusively along the Antarctic continent. Modeling ocean physics in this region has remained challenging for global coarse resolution models [e.g., Caldeira and Duffy, 2000; Doney and Hecht, 2002; Doney et al., 2004], although recent high-resolution simulations suggest a substantial improvement once the OGCMs start to resolve the mesoscale dynamics more explicitly [e.g., Lachkar et al., 2007]. Lacking an eddy-resolving model among our OGCMs, we have to accept this shortcoming. We nevertheless note that the model with the highest skill score (NCAR), suggests a relatively uniform meridional distribution, similar to what the mean of all models suggest. Another concern is the relatively high degree of posterior correlation in the fluxes estimated for the three oceanic regions south of $44^{\circ} \mathrm{S}$. This leads to potential instabilities in the solutions, such that the flux in each region may shift strongly in response to small changes in the data, while keeping the total flux invariable.

[39] Despite the large regional differences within the Southern Ocean, the fluxes estimated by the individual models converge at the level of the entire Southern Ocean to the reported $-0.34 \pm 0.20 \mathrm{Pg} \mathrm{C} \mathrm{a}^{-1}$ (individual model estimates range from -0.72 to $-0.15 \mathrm{Pg} \mathrm{C} \mathrm{a}^{-1}$ ). Thus, it appears as if the data constraints used in the inversion provide a "clamp" on the fluxes at the scale of the entire Southern Ocean, but that this clamp is weak at the regional level, exposing the large model-to-model differences in ocean physics in the Southern Ocean.

[40] As noted above, the uncertainty associated with the $p \mathrm{CO}_{2}$ based flux estimates is mostly caused by possible sampling biases, uncertainties in the magnitude of the adjustment needed to bring all observations to a common date, and the uncertainties associated with the gas transfer velocity. The error that we assigned to the flux estimates is based on the use of 6 different models of the gas transfer velocity, so that this error already has been taken into account explicitly. If we consider that the extreme case, i.e., the cubic wind speed relationship of Wanninkhof and McGillis [1999] is quite likely the least likely to be correct [see, e.g., Ho et al., 2006], the error in the Southern Ocean stemming from errors in the gas transfer velocity may not exceed $0.1 \mathrm{Pg} \mathrm{Ca}^{-1}$. The sampling bias is more difficult to assess, but we note that the new $p \mathrm{CO}_{2}$ climatology has over 1 million observations south of $44^{\circ} \mathrm{S}$, with reasonably good coverage in all seasons. Using the concurrently sampled temperature as a proxy, Takahashi et al. [2008] estimate the potential bias in the annual mean oceanic $p \mathrm{CO}_{2}$ in the POOZ to be around $\pm 2 \mu \mathrm{atm}$, which translates into a possible flux bias of around $\pm 0.10 \mathrm{Pg} \mathrm{C} \mathrm{a}^{-1}$ for this region. In the SIZ, the sampling is poorer, particularly in the vicinity of sea-ice. The observations analyzed by Takahashi et al. [2008] suggest that in this area the waters in the vicinity of sea-ice have very high $p \mathrm{CO}_{2}$ during wintertime, prompting them to develop and apply a parameterization to capture this effect. This parameterization is responsible for much of the large increase in the $p \mathrm{CO}_{2}$ climatology in the SIZ between the 2002 and 2008 version of the climatology [see Takahashi et al., 2008, Figure 11]. This parameterization needs to be reevaluated once new data become available, but its influence on the error of the SIZ flux is unlikely much larger than 0.1 to $0.2 \mathrm{Pg} \mathrm{C} \mathrm{a}^{-1}$. Taken together, our reevaluation of the error of the $p \mathrm{CO}_{2}$-based flux estimate in the Southern Ocean suggests that it is likely not larger than about $\pm 0.25 \mathrm{Pg} \mathrm{C} \mathrm{a}^{-1}$ (RMS), only slightly larger than our original error estimate of $\pm 0.17 \mathrm{Pg} \mathrm{C} \mathrm{a}^{-1}$.

[41] In summary, the relatively small net uptake fluxes in the Southern Ocean of $\sim-0.3 \mathrm{Pg} \mathrm{C} \mathrm{a}^{-1}$ appear robust in both estimates. This conclusion supports a growing list of studies that came to similar results using rather different approaches, such as atmospheric inversion studies [e.g., Gurney et al., 2002; Roy et al., 2003] (more in section 3.4 


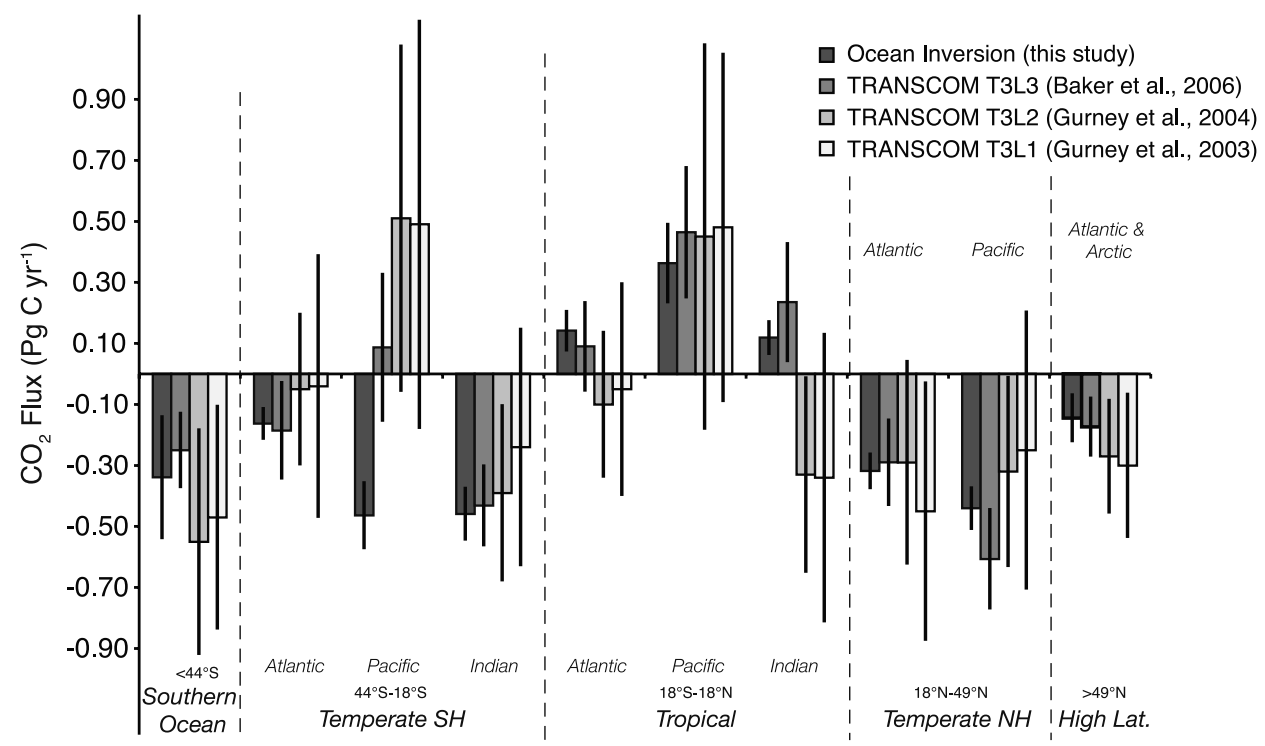

Figure 3. Comparison of the ocean inversion estimate of the contemporary air-sea $\mathrm{CO}_{2}$ flux with the three atmospheric $\mathrm{CO}_{2}$ inversion setups considered by TransCom. Level 1 is the annual mean inversion setup [Gurney et al., 2002, 2003], level 2 is the cyclostationary seasonal mean inversion setup [Gurney et al., 2004], and level 3 is the interannually varying setup [Baker et al., 2006]. For levels 1 and 2, the fluxes are based on mean data from 1992 through 1996, whereas for level 3, the fluxes are the average fluxes for the period 1991 through 2000. For simplicity, the "within" (data) error and the "between" (model) error of the TransCom estimates have been combined to a single error by RMS. For the level 1, the results from an inversion without the Darwin station are plotted. Positive fluxes indicate outgassing.

below) and estimates based on surface ocean DIC and alkalinity measurements [McNeil et al., 2007]. However, the regional distribution within the Southern Ocean remains to be firmly established. In particular, the possible net outgassing of carbon in the Antarctic, a feature that appears for the first time in the 2008 version of the $p \mathrm{CO}_{2}$ climatology needs to be viewed with caution (see Figure S2). Despite these significant differences at the regional level, the agreement between the inversely estimated contemporary fluxes and those estimated from the most recent $p \mathrm{CO}_{2}$ climatology is remarkable, particularly considering that they are based on entirely independent constraints and assumptions. In the case of the ocean inversion, the flux estimates are based solely on information provided by ocean interior carbon data, which are interpreted with the help of transport and mixing estimates stemming from a suite of OGCMs. In the case of the new $p \mathrm{CO}_{2}$-based estimates, the main constraint are the $p \mathrm{CO}_{2}$ observations, from which the flux is estimated using assumptions about the gas transfer velocity.

\subsection{Comparison With Other Air-Sea Flux Estimates}

[42] The "top down" estimates of the air-sea fluxes based on the interannual inversion of atmospheric $\mathrm{CO}_{2}$ (TransCom-3 Level 3) agree remarkably well with the "bottom up" estimates based on the oceanic inversion or on the surface ocean $p \mathrm{CO}_{2}$ data with the exception of the temperate South Pacific (Figure 1). Such atmospheric inversions are methodologically similar to that used here for the ocean, except that they can resolve temporal changes in the fluxes by considering the temporal evolution of the spatial distribution of atmospheric $\mathrm{CO}_{2}$. In the case of the interannually varying
TransCom-3 Level 3 inversion, monthly mean atmospheric $\mathrm{CO}_{2}$ data for each month from 1988 until 2003 were used, resulting in monthly mean fluxes across this period [Baker et al., 2006]. In prior TransCom-3 experiments (level 2 and level 1), less temporal change is considered, as level 2 inverts the monthly mean data of a climatologically averaged year (1992-1996) [Gurney et al., 2004], and level 1 inverts just the annual mean atmospheric $\mathrm{CO}_{2}$ distribution (1992-1996); that is, no temporal change is considered [Gurney et al., 2002, 2003].

[43] One would expect the atmospheric inversion results to be in reasonably good agreement with the ocean $p \mathrm{CO}_{2}$ based estimates, as the latter are used as prior estimates in the inversion of atmospheric $\mathrm{CO}_{2}$, so that deviations from these estimates should occur only if these priors turn out to be inconsistent with the atmospheric $\mathrm{CO}_{2}$ data. However, in the TransCom inversions, these priors were assigned large uncertainties, so that the constraint from the priors is relatively weak (a notable exception is the lack of consideration of possible covariances, which can lead to biases even in the presence of weak priors [Jacobson et al., 2007a]). This is illustrated by the fact that the mismatch between the "top down" results from the atmospheric inversion and the "bottom up" estimates is substantially larger for the seasonal mean (cyclostationary) setup (TransCom 3 level 2), and for the annual mean setup (TransCom 3 level 1) (Figure 3), despite the fact that all atmospheric inversions used the same priors.

[44] Therefore, the mismatches between the top down and bottom up estimates reflect primarily the relatively small information content of atmospheric $\mathrm{CO}_{2}$ with regard to 
air-sea $\mathrm{CO}_{2}$ fluxes (see detailed discussion by Jacobson et al. [2007a]). This problem is particularly severe in the tropics and the temperate Southern hemisphere, as these regions have an inadequate number of atmospheric observation stations. As a result, small changes in the selection of the stations [Gurney et al., 2008; Patra et al., 2006] or in the setup of the inversion (Figure 3 ) can lead to large shifts in the inversely estimated fluxes. The regions that seem to be most affected are the tropical Indian Ocean and the temperate South Pacific. In essence, the atmospheric $\mathrm{CO}_{2}$ inversion treats these areas as unconstrained, permitting it to alter their fluxes substantially in order to match better data constraints elsewhere.

[45] This appears to be less the case in the Southern Ocean, where the large number of atmospheric $\mathrm{CO}_{2}$ observation stations and the absence of land make the air-sea flux results from the atmospheric $\mathrm{CO}_{2}$ inversions more robust [Gurney et al., 2002]. The level 3 inversion result is in excellent agreement with the two bottom up estimates in the region south of $44^{\circ} \mathrm{S}$ (Figure 1a) in suggesting a relatively small contemporary carbon sink in this region $(-0.25 \pm$ $\left.0.13 \mathrm{Pg} \mathrm{C} \mathrm{a}^{-1}\right)$. This finding of such a small sink in the atmospheric inversion is remarkable, as a large carbon sink of $-0.88 \mathrm{Pg} \mathrm{C} \mathrm{a}^{-1}$ was used as prior, on the basis of the earlier $p \mathrm{CO}_{2}$ climatology of Takahashi et al. [2002] (see Figure S2). With this substantial reduction of the Southern Ocean carbon sink, the level 3 inversion continued a tendency exhibited by all TransCom inversions, i.e., to reduce the large prior carbon sink in that area [e.g., see also Roy et al., 2003]. We thus regard this tendency as robust.

[46] The reasons why the interannually varying inversion (level 3) results agree better with the bottom up estimates than the level 1 and 2 results are not known presently. The slightly different time periods can be excluded as an explanation (level 3 uses data from 1992 through 2000, while level 1 and 2 use data from 1992 through 1996 only), since Baker et al. [2006] showed only modest changes in the mean fluxes between the two periods. However, these three studies used slightly different global constraints, such as atmospheric growth rate and fossil fuel emissions for the same periods, possibly causing shifts in the fluxes over ill constrained regions, such as the South Pacific. Another candidate explanation are differences in the employed atmospheric $\mathrm{CO}_{2}$ network, as air-sea fluxes from atmospheric inversion studies tend to be rather sensitive to changes in the selection of observing stations [see, e.g., Patra et al., 2006; Gurney et al., 2008]. A last possible explanation is that the interannually varying inversion setup is less prone to aliasing effects between atmospheric transport and atmospheric $\mathrm{CO}_{2}$ observations, an effect that is best known on diurnal or seasonal timescales and often referred to as "rectifier" [Denning et al., 1995].

[47] The air-sea fluxes simulated by the ocean forward models of OCMIP-2 reveal remarkably little difference from the ocean inversion fluxes, with the Southern Ocean standing out as an exception. This comparison is particularly relevant, as several of the OGCMs used for the ocean inverse were also employed as the circulation component for the coupled biogeochemistry circulation models in
OCMIP-2. Therefore, some of the differences between the fluxes can be interpreted as reflecting the difference between a run where observations are "assimilated" and a run where the model's equations are integrated forward in time without such observational constraints. Given the entirely different nature of these two simulations, the remarkably low level of difference between the inversion and the forward runs suggests high robustness in the modeling of the oceanic carbon cycle. However, this conclusion only holds for the mean fluxes of all models and for the contemporary fluxes. Larger differences emerge for individual models, as well as for the two components, i.e., natural and anthropogenic $\mathrm{CO}_{2}$ fluxes [Mikaloff Fletcher et al., 2006, 2007]. The large discrepancy between forward and inverse results in the Southern Ocean illustrates this. Here the forward models suggest a sink that is more than twice as large as that found by the inversion. A more detailed analysis reveals that the main reason for the much higher contemporary uptake of $\mathrm{CO}_{2}$ in the forward models is because of a weaker outgassing flux of natural $\mathrm{CO}_{2}$ and not because of a stronger uptake of anthropogenic $\mathrm{CO}_{2}$. Mikaloff Fletcher et al. [2007] hypothesized that the outgassing flux of natural $\mathrm{CO}_{2}$ could be biased low in the OCMIP-2 models owing to errors in their common biological model (R. Najjar and J. C. Orr, Design of OCMIP-2 Simulations of Chlorofluorocarbons, the Solubility Pump and Common Biogeochemistry, 1998), particularly errors associated with the seasonal cycle [Najjar et al., 2007].

[48] In summary, the comparison of four independent means of estimating the contemporary net air-sea $\mathrm{CO}_{2}$ flux depict a rather consistent picture of the distribution of the time-mean sources and sinks of atmospheric $\mathrm{CO}_{2}$ over the ocean. The estimates that we have most confidence in, i.e., the oceanic inversion and the oceanic $p \mathrm{CO}_{2}$-based estimates show an even greater consistency. But also the other flux estimates do not point toward a substantial unrecognized gap in our ability to quantify these fluxes as nearly all differences can be explained by the known biases in the various estimates. It is particulary noteworthy that both the surface ocean $p \mathrm{CO}_{2}$-based estimates and the atmospheric $\mathrm{CO}_{2}$ inversion-based estimates have converged through subsequent iterations to the flux estimates suggested by the oceanic inversion (Figures S2 and 3). However, we need to be aware of the limitations of this comparison. The biggest caveat is that this comparison is limited to the long-time mean fluxes of the 1990s and early 2000s.

\subsection{Caveats}

[49] The convergence of the various independent estimates of the time-mean air-sea $\mathrm{CO}_{2}$ fluxes is encouraging, but needs to be viewed with caution given a number of caveats. One area of potential concern for the ocean inverse estimates is the fact that the inverted data are not directly observed quantities, but derived properties with all their associated uncertainties. While we have made substantial efforts to quantify the resulting errors in the inversely estimated fluxes [see Mikaloff Fletcher et al., 2006, 2007], we cannot exclude the possibility for stronger biases. One nagging indication of such a potential problem is the presence of a substantial residual in the $\Delta C_{\text {gas ex }}$ tracer after 
the inversion for the fluxes of natural $\mathrm{CO}_{2}$ [Mikaloff Fletcher et al., 2007, Figure 7]. Although we have argued that the majority of this residual is due to common problems of the ocean transport models, some fraction could also be the result of biases in $\Delta C_{\text {gas ex }}$ itself with presently unknown consequences for the fluxes.

[50] Another area of concern is the presence of possibly substantial (and mostly ill constrained) interannual to decadal variability in the upper ocean carbon cycle [e.g., Le Quéré et al., 2000; McKinley et al., 2004; Gruber et al., 2002; Feely et al., 1999] and possible long-term trends [e.g., Takahashi et al., 2003; Lefèvre et al., 2004; Wetzel et al., 2005; Takahashi et al., 2006; Le Quéré et al., 2007; Schuster and Watson, 2007; Lovenduski et al., 2008]. Although the various estimates discussed here pertain to the decade of the 1990s and early 2000s, they may reflect possible temporal changes in the fluxes rather differently. The ocean inverse fluxes are likely those least affected by changes on interannual to decadal timescales, as ocean mixing will smooth much of the impact of flux variability on the ocean's interior distribution of the tracers. In addition, the basis functions are fitted across data from water parcels across a wide distribution of water ages, so that we expect the ocean inverse fluxes to reflect the time-mean fluxes over much of the 20th century, although the fact that the ocean circulation models were forced with heat and freshwater fluxes from primarily the second half of that century could lead to a slight bias toward this latter period.

[51] Of greater concern is the possibility of a long-term (multidecadal) trend in the (natural) carbon fluxes [Matsumoto and Gruber, 2005] that would violate our assumption of a long-term steady state natural carbon cycle. Keeling [2005] suggested that ocean warming and the resulting increase in oceanic stratification could have led to an outgassing of natural $\mathrm{CO}_{2}$ of about $7 \pm 10 \mathrm{Pg} \mathrm{C}$ since 1860 . It is reasonable to expect that a substantial fraction of this outgassing occurred since the early 1970 s when global surface temperature began to rise quickly [Jones and Moberg, 2003]. Even so, the expected outgassing of natural $\mathrm{CO}_{2}$ for the 1990 s may amount to not more than perhaps $2 \mathrm{Pg} \mathrm{C}$, or less than $0.2 \mathrm{Pg} \mathrm{C} \mathrm{a}^{-1}$, which is less than $10 \%$ of the total anthropogenic $\mathrm{CO}_{2}$ uptake over this period [Sabine and Gruber, 2005].

[52] The $p \mathrm{CO}_{2}$-based estimate reflects the instantaneous fluxes, although averaged over the time period that measurements for a given region are available (most of the observations stem from the 1990s). This varies considerably between the regions, and a proper assessment of its impact requires a separate study. Some of the interannual variability signal has been removed from this climatology, as Takahashi et al. [2008] decided to remove the observations from the tropical Pacific taken during peak El Niño events, but the impact of adding these observations back is relatively small (less than $0.1 \mathrm{Pg} \mathrm{C} \mathrm{a}^{-1}$ change in the eastern tropical Pacific). Should a net outgassing of natural $\mathrm{CO}_{2}$ exist, this net outgassing would have to be added to the $p \mathrm{CO}_{2}$ based estimate of the oceanic uptake of anthropogenic $\mathrm{CO}_{2}$.

\subsection{Attribution and Processes}

[53] As is evident from Figure 1b, the contemporary flux arises as a result of a complex superposition of the anthro- pogenic and natural $\mathrm{CO}_{2}$ fluxes, with the former going into the ocean everywhere, and the latter exhibiting a pattern of outgassing in the tropics and uptake in the midlatitudes and northern high latitudes. By definition, the flux of riverderived natural $\mathrm{CO}_{2}$ is out of the ocean everywhere, with a magnitude that is considerably smaller than either of the two other components.

[54] The Southern Ocean differs from the high northern latitudes as it represents a strong source of natural $\mathrm{CO}_{2}$ to the atmosphere. At the same time, this region represents the largest sink region for anthropogenic $\mathrm{CO}_{2}$. Thus, as displayed in greater detail in Figures $4 \mathrm{c}$ and $4 \mathrm{~d}$, the contemporary small sink in the Southern Ocean is caused by a near cancellation between a substantial outgassing flux of natural $\mathrm{CO}_{2}$, which presumably existed already in preindustrial times, and a large uptake flux of anthropogenic $\mathrm{CO}_{2}$, which has grown over time and is expected to increase further as atmospheric $\mathrm{CO}_{2}$ continues to rise. Presently, the Southern Ocean takes up more than a third of the global anthropogenic $\mathrm{CO}_{2}$, yet it covers only $18 \%$ of the global surface ocean area.

[55] High uptake rates of anthropogenic $\mathrm{CO}_{2}$ are associated with those regions where waters that have not been in contact with the atmosphere for some time come to the surface and are exposed to the increased $\mathrm{CO}_{2}$ in the atmosphere [Sarmiento et al., 1992; Orr et al., 2001; Mikaloff Fletcher et al., 2006]. In the Southern Ocean, the upwelling of Circumpolar Deep Water (CDW) with very low concentrations of $C_{\text {ant }}$ provides a large potential for the uptake of anthropogenic $\mathrm{CO}_{2}$ (Figure 5a). $C_{\text {ant }}$ is low in upwelling CDW because it stems in part from the mid-depth return flow of deep waters from the Indian and Pacific Ocean [Schmitz, 1995]. Most of this uptake potential is realized as the upwelled waters that are being pushed northward at the surface by the Ekman drift are exposed to the elevated atmospheric $\mathrm{CO}_{2}$ in the presence of high windspeeds, which accelerate the uptake. The resulting anthropogenic $\mathrm{CO}_{2}$-rich waters are then transported to depth as Antarctic Intermediate Waters (AAIW) and Subantarctic Mode Waters (SAMW) discernible in Figure 5a by the deep penetration of anthropogenic $\mathrm{CO}_{2}$ at midlatitudes of the Southern hemisphere [see also Gruber, 1998; Sabine et al., 2004]. Globally, this is the single most important pathway for the oceanic uptake of anthropogenic $\mathrm{CO}_{2}$, causing a circumpolar ring of strong uptake flux centered in the Polar Frontal Zone (between the Polar Front and the Subantarctic Front) and in the Subantarctic Zone (Figure 4d).

[56] The source and sink pattern of natural $\mathrm{CO}_{2}$ inferred by the inversion can be traced back to the ocean interior distribution of $\Delta C_{\text {gas ex }}$, in particular its gradients (Figure $5 \mathrm{~b}$ ). Waters that have low concentrations of $\Delta C_{\text {gas ex }}$ must have lost natural $\mathrm{CO}_{2}$ to the atmosphere the last time they were in contact with the atmosphere, and vice versa for waters with high $\Delta C_{\text {gas ex }}$ concentrations. Closer inspection of the $\Delta C_{\text {gas ex }}$ distribution in the Southern Ocean reveals that the CDW upwelling in this region is characterized by elevated $\Delta C_{\text {gas ex }}$ concentrations, whereas the $\Delta C_{\mathrm{gas}}$ ex concentrations in the core of the AAIW ( $\sigma \theta$ between 27.00 and 27.50) are substantially depleted, reflecting the strong outgassing of natural $\mathrm{CO}_{2}$ as waters flow northward in the Southern Ocean (Figure $5 \mathrm{~b}$ ). By contrast, SAMW has rather high $\Delta C_{\text {gas ex }}$ 
a

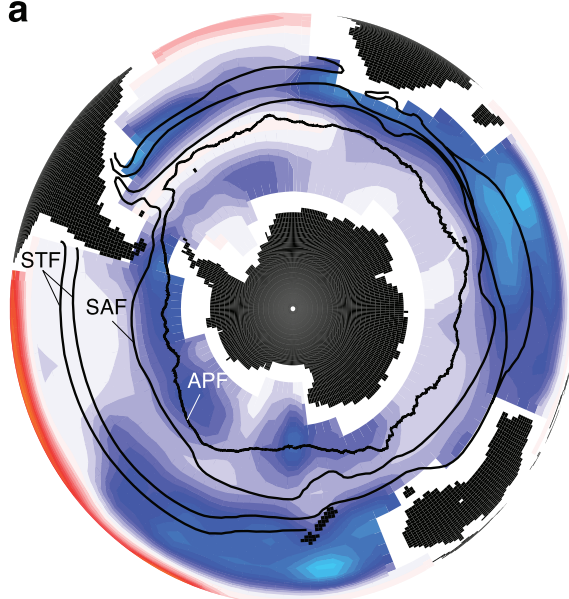

CONTEMPORARY $\mathrm{CO}_{2}$ FLUX (INVERSION)

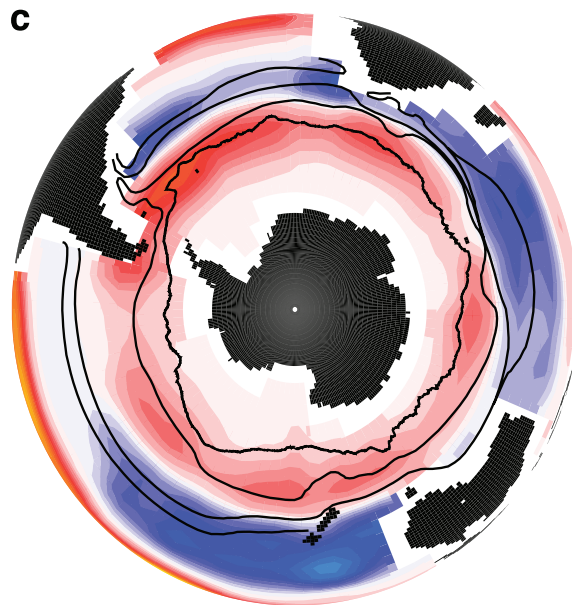

NATURAL $\mathrm{CO}_{2}$ FLUX (INVERSION) b

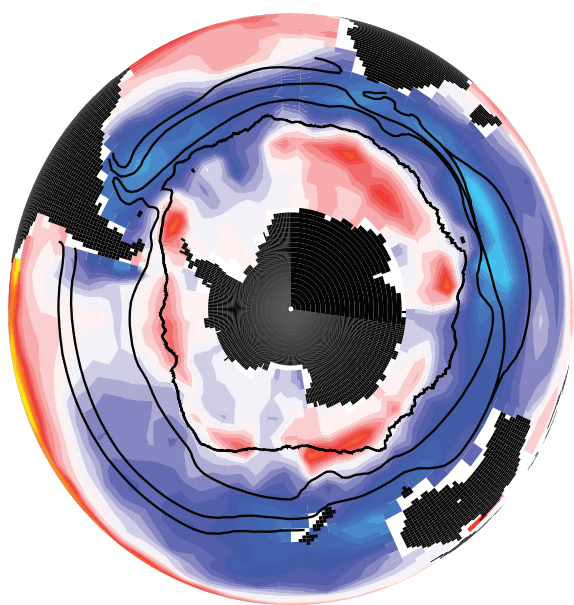

CONTEMPORARY $\mathrm{CO}_{2}$ FLUX $\left(\triangle \mathrm{p} \mathrm{CO}_{2} B A S E D\right)$

d

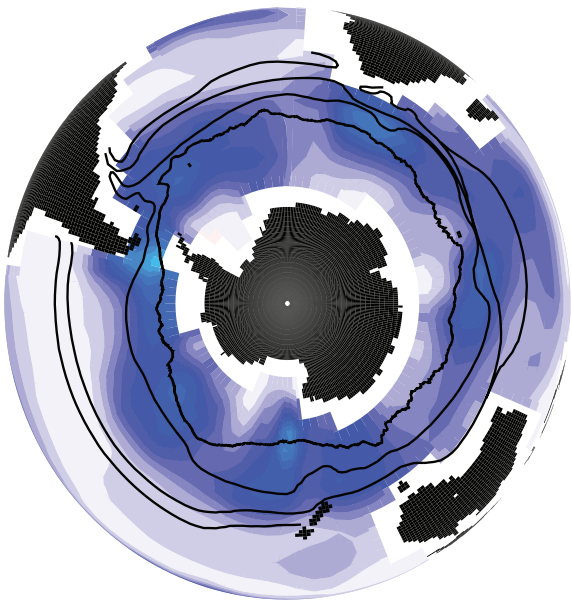

ANTHROPOGENIC $\mathrm{CO}_{2}$ FLUX (INVERSION)

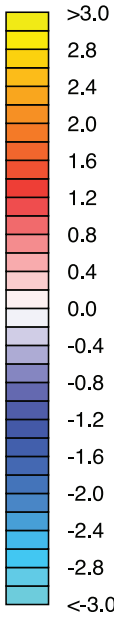

$\left(\mathrm{mol} \mathrm{m} \mathrm{m}^{-2} \mathrm{yr}^{-1}\right)$

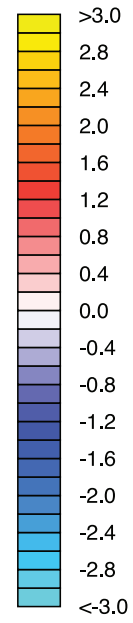

$\left(\mathrm{mol} \mathrm{m}^{-2} \mathrm{yr}^{-1}\right)$

Figure 4. Polar stereographic maps of air-sea $\mathrm{CO}_{2}$ fluxes $\left(\mathrm{mol} \mathrm{m}^{-2} \mathrm{a}^{-1}\right)$ (positive (red): outgassing, negative (blue): uptake). (a) Inverse estimate of the contemporary air-sea flux (nominal 1995), i.e., the sum of natural and anthropogenic $\mathrm{CO}_{2}$. (b) Oceanic $p \mathrm{CO}_{2}$-based estimate of the air-sea $\mathrm{CO}_{2}$ flux based on Takahashi et al. [2008] (nominal year of 2000). (c) Inverse estimates of the air-sea flux of natural $\mathrm{CO}_{2}$, which is equivalent to the air-sea flux of $\mathrm{CO}_{2}$ in preindustrial times. (d) Inverse estimate of the air-sea flux of anthropogenic $\mathrm{CO}_{2}$ for a nominal year of 1995. The lines show the dominant fronts in the Southern Ocean, going equatorward from Antarctica: Antarctic Polar Front (APF), Subantarctic Front (SAF), and Southern and Northern Subtropical Fronts (STF). The maps for the inverse estimates were constructed by distributing the inverse flux estimates within each region according to the flux pattern that was used when releasing the dye tracers from the surface.

concentrations, reflecting the uptake of natural $\mathrm{CO}_{2}$ as some of the waters from the south continue to be pushed northward. Some of this high $\Delta C_{\text {gas ex }}$, particularly in the water masses shallower than SAMW, may also reflect the entrainment of southward flowing waters that took up natural $\mathrm{CO}_{2}$ from the atmosphere during their transit in the temperate latitudes of the southern hemisphere (Figure $4 \mathrm{~b}$ ). Also discernible in Figure $5 \mathrm{~b}$ is the high $\Delta C_{\text {gas ex }}$ tongue of southward flowing North Atlantic Deep Water (NADW) in the deeper parts of the Atlantic, which is the primary cause for the existence of a substantial interhemispheric transport of natural carbon [Mikaloff Fletcher et al., 2007].

\section{Ocean Transport}

[57] The contemporary oceanic transport of carbon (Figure 6, blue arrows) inferred from the ocean inverse flux estimates shows southward transport throughout much of the Atlantic, strong equatorward transport in the Pacific, and a small northward transport throughout the Indian Ocean. The contemporary global net transport across the equator is 


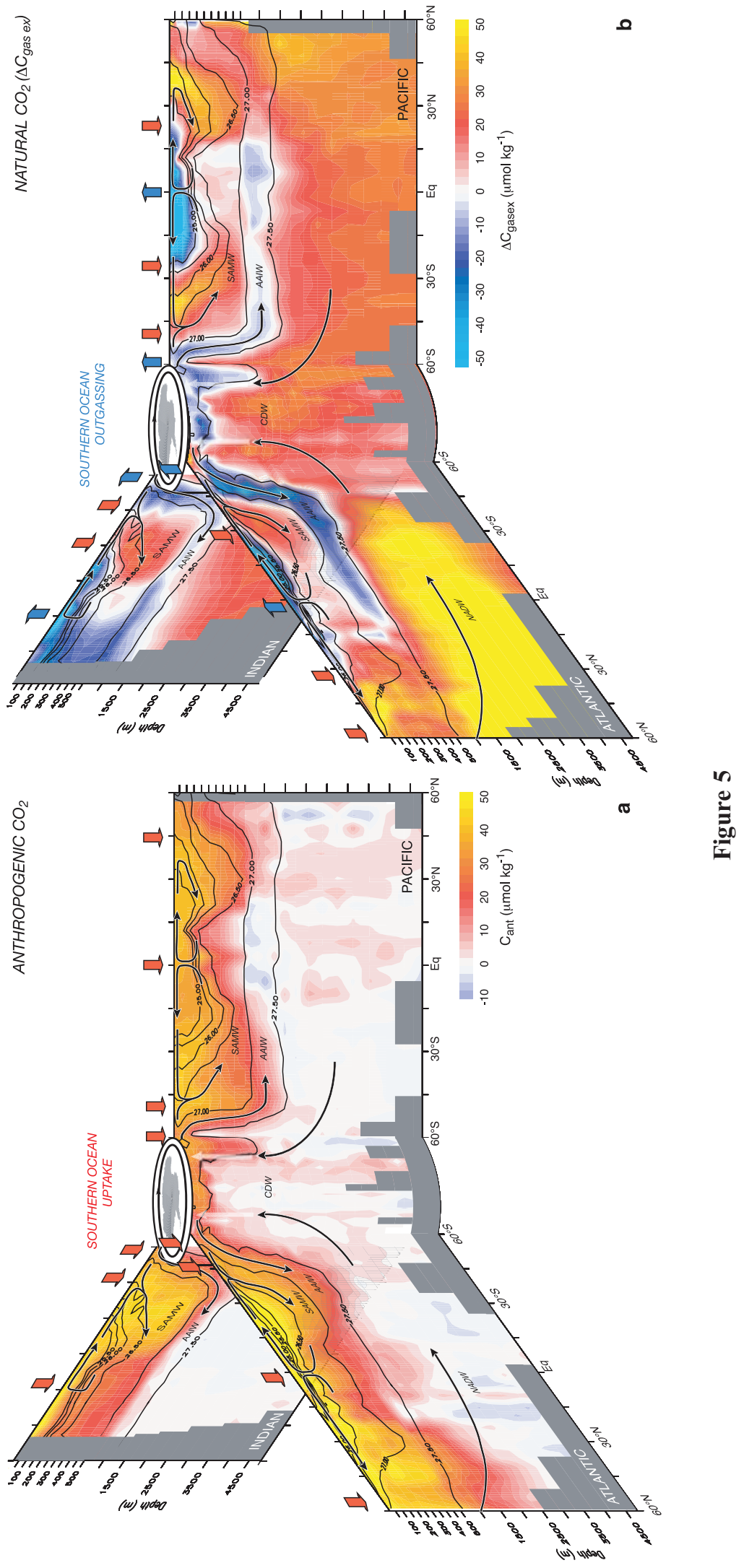




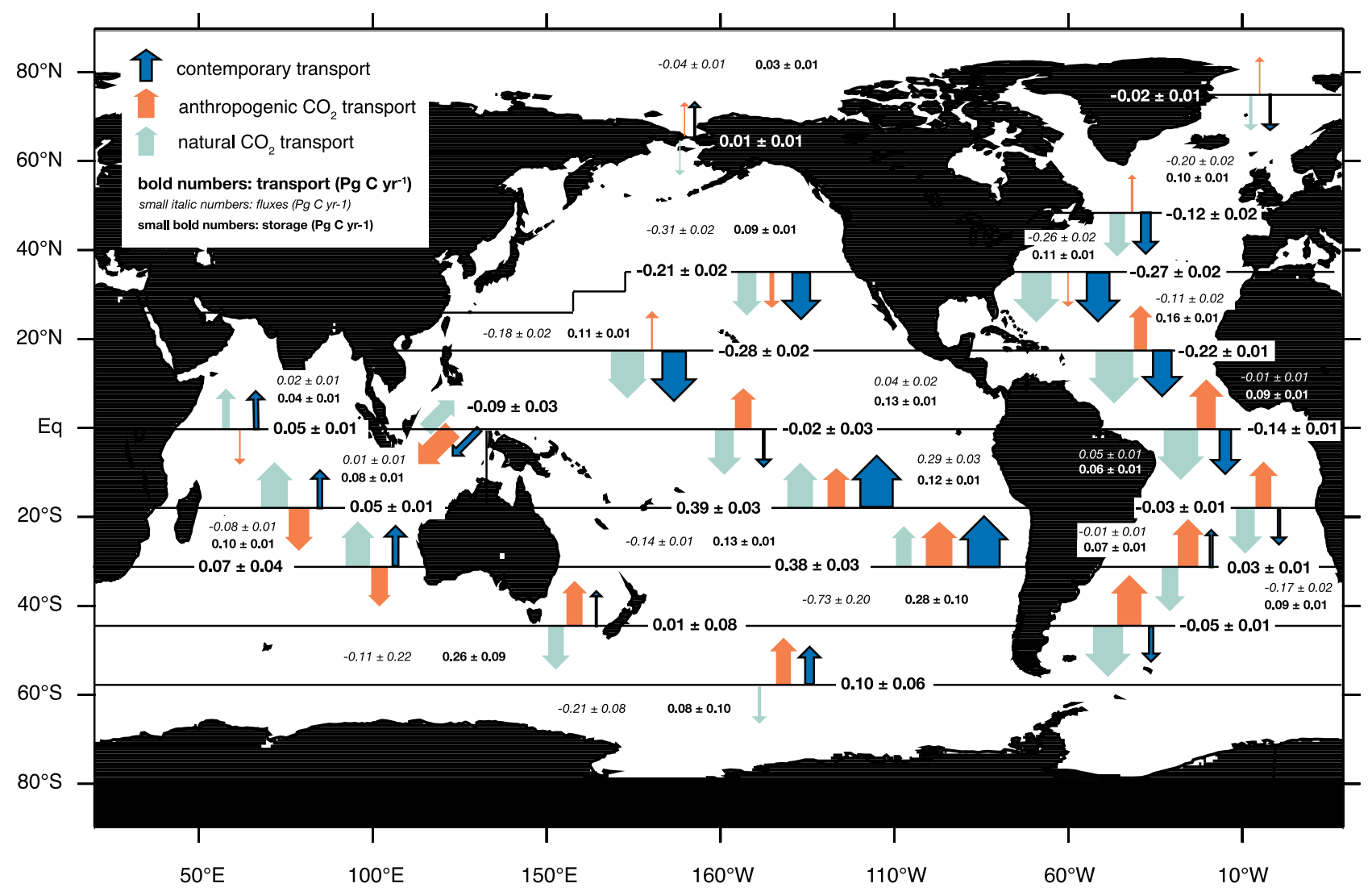

Figure 6. Global map of the contemporary transport of carbon (blue arrows with large bold numbers) and of its components (natural carbon with green arrows and anthropogenic carbon with red arrows) based on the inverse flux estimates (small italic numbers). Depicted are the weighted mean estimates and their weighted mean standard deviation, all in $\mathrm{Pg} \mathrm{C} \mathrm{a}^{-1}$. Also shown are the storage estimates, i.e., the integrated rates of change in $D I C$ arising from the anthropogenic $\mathrm{CO}_{2}$ perturbation.

relatively small $\left(\sim-0.2 \mathrm{Pg} \mathrm{C} \mathrm{a}^{-1}\right)$, supporting a string of studies that all demonstrated a relatively small global interhemispheric transport of carbon [e.g., Keeling and Peng, 1995; Murnane et al., 1999; Sarmiento et al., 2000] in contrast to the original suggestion by Keeling et al. [1989] of a large interhemispheric transport of the order of $1 \mathrm{Pg} \mathrm{C}$ $\mathrm{a}^{-1}$ (see more detailed discussion by Mikaloff Fletcher et al. [2007]).

[58] The contemporary southward transport of carbon in the Atlantic is much smaller than that for natural carbon (green arrows), as the latter is compensated by a substantial northward transport of anthropogenic carbon (red arrows). With the expected continued uptake of anthropogenic $\mathrm{CO}_{2}$ from the atmosphere and the resulting increase in the northward transport of anthropogenic $\mathrm{CO}_{2}$, one can soon expect a reversal of the sign of the transport of total carbon in the South Atlantic, a change that we infer to have taken place already in the transport at about $31^{\circ} \mathrm{S}$. A similar compensation between the transport of natural and anthropogenic carbon occurs in the Indian Ocean, where the transport of anthropogenic carbon is southward, whereas the natural carbon transport is northward. In contrast, the two component fluxes enhance each other in the South Pacific, resulting in roughly a doubling of the total northward transport of carbon in this region. At the equator and in the North Pacific, both compensation and enhancement occur. Overall, as was the case for the air-sea fluxes, the superposition of natural and anthropogenic carbon transports results in a complex pattern of the contemporary (total) carbon transport, whose structure can only be understood by considering separately

Figure 5. Ocean interior distributions of the tracers reflecting the exchange of $\mathrm{CO}_{2}$ across the air-sea interface, displayed as global-scale section plots organized around the Southern Ocean in the center. (a) Distribution of anthropogenic $\mathrm{CO}_{2}$, $C_{\text {ant }}$, estimated using the $\Delta C^{*}$ method of Gruber et al. [1996]. (b) Distribution of the gas exchange component of natural $\mathrm{CO}_{2}, \Delta C_{\text {gas ex }}$, following Gruber and Sarmiento [2002]. The inversion interprets these distributions by determining, given ocean circulation and mixing, a set of surface ocean fluxes that most closely matches these observations. Also shown are isolines of potential density anomalies, $\sigma_{\theta}$ (density referenced to the ocean surface minus $1000 \mathrm{~kg} \mathrm{~m}^{-3}$ ), along which most of the oceanic flow occurs. Major ocean circulation features are indicated by schematic arrows. Figure 5 is based on data taken from GLODAP [Key et al., 2004]. NADW: North Atlantic Deep Water, CDW: Circumpolar Deep Water; SAMW: Subantarctic Mode Water; AAIW: Antarctic Intermediate Water. 


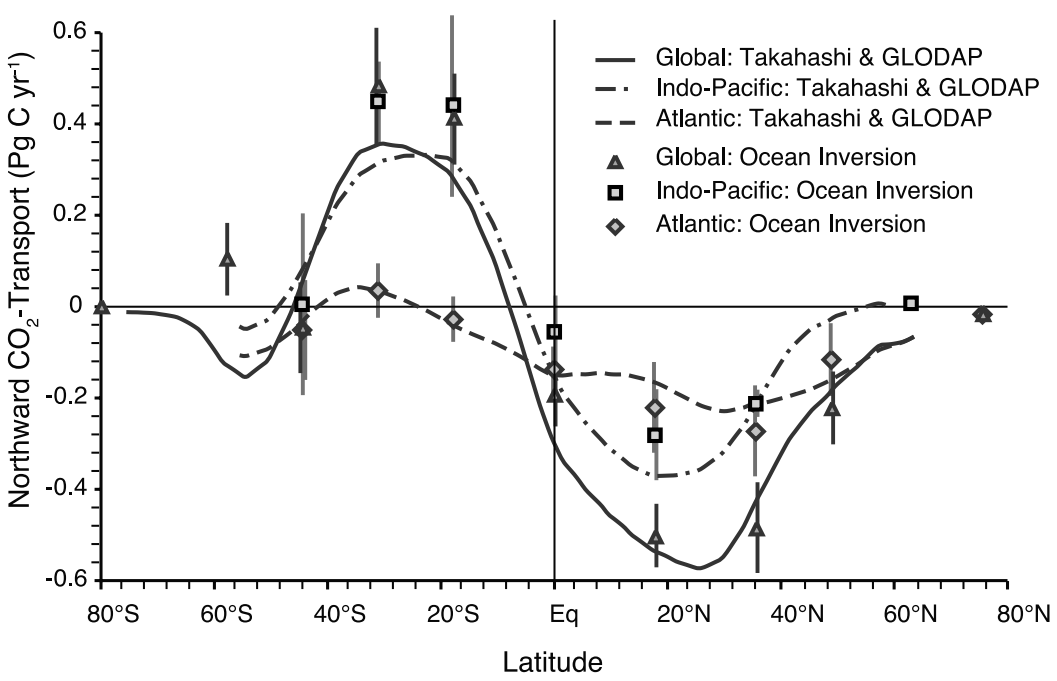

Figure 7. Comparison of contemporary transport of carbon for the global ocean and for the individual ocean basins between the estimates inferred from the inverse flux estimates (this study, symbols) and those inferred from the $p \mathrm{CO}_{2}$-based flux estimates of Takahashi et al. [2008] (lines). Both estimates infer a contemporary net southward transport of carbon across the equator with a magnitude of between -0.2 and $-0.3 \mathrm{Pg} \mathrm{C} \mathrm{a}^{-1}$.

the transports of the natural and anthropogenic carbon components.

[59] The concurrent availability of databased estimates of the air-sea $\mathrm{CO}_{2}$ flux and of the oceanic inventory of anthropogenic $\mathrm{CO}_{2}$ permits us to compute a second, independent estimate of the contemporary $\mathrm{CO}_{2}$ transport. The comparison of this new $p \mathrm{CO}_{2}$ based estimate (equation (1)) with that based on the ocean inversion (Figure 7) reveals a remarkably consistent depiction of the global-scale oceanic transport, and how the individual ocean basins contribute to it. The $p \mathrm{CO}_{2-}$ based transport estimate confirms the previously identified net southward transport throughout much of the Atlantic, and the strong convergence toward the equator in the combined Indian and Pacific. Both estimates identify a small hemispheric asymmetry, with a southward transport across the equator of between -0.2 and $-0.3 \mathrm{Pg} \mathrm{C} \mathrm{a}{ }^{-1}$, contributed to by both the Atlantic and Indo-Pacific basins. The agreement is better in the Atlantic than in the Indo-Pacific, where the $p \mathrm{CO}_{2}$-based transport estimates is consistently lower than the inverse estimates south of about $30^{\circ} \mathrm{N}$, resulting in a considerable difference of about $0.1 \mathrm{Pg} \mathrm{C} \mathrm{a}^{-1}$ in the northward transport in the Indo-Pacific (and global) at temperate latitudes of the Southern hemisphere. As was the case with the air-sea fluxes, the biggest difference occurs in the Southern Ocean, where our inverse estimates indicate northward transport at about $60^{\circ} \mathrm{S}$, whereas the $p \mathrm{CO}_{2}$ based estimates suggest a southward transport, highlighting again the disagreement in this critical region.

[60] Hydrographic transport estimates of contemporary (total) carbon transport are available only for the Atlantic ocean (see Figure S3). To put all estimates on the same basis, we normalized all transport estimates to a Bering Strait throughflow of zero; that is, we removed from each transport estimate their reported transport through Bering Strait. This carbon transport through Bering Strait is caused by the net mass transport through this strait and represents a nondiver- gent component of the carbon transport through the Atlantic; that is, it does not lead to surface fluxes of carbon. As our transport estimates are based on surface fluxes, they do not include the Bering Strait transport explicitly, so that we take a zero transport through this strait as a reference point.

[61] The tendency of the inverse and $p \mathrm{CO}_{2}$-based transport estimates for a southward reduction in the southward transport in the South Atlantic agrees well with the direct transport estimates by Holfort et al. [1998], except that the Holfort estimate suggests a consistently stronger southward transport with a mean difference of about $0.14 \mathrm{Pg} \mathrm{C} \mathrm{a}^{-1}$. It is conceivable that this offset is due to a bias in their estimated Bering Strait transport, which we subtracted, as small relative errors in this large carbon transport causes large, but uniform offsets in the net carbon transport across all considered sections. There is also good agreement between our inverse transport estimates and those of Holfort et al. [1998] with regard to the strong compensatory tendency between the southward transport of natural carbon and the northward transport of anthropogenic carbon. The comparison of the two transport components also reveals that the offset between the estimates is driven entirely by the natural carbon transports, supporting our hypothesis that a potential bias in the assigned Bering Strait transport is causing the too strong southward transports in the estimates by Holfort et al. [1998].

[62] The results of a comparison of the contemporary transports in the North Atlantic are much more mixed, in part because of the disparity in the observational estimates. While both our transport estimates of about $-0.2 \mathrm{Pg} \mathrm{C} \mathrm{a}^{-1}$ across $24^{\circ} \mathrm{N}$ agree well with that of Brewer et al. [1989], huge differences emerge in the comparison with the newer transport estimates of Macdonald et al. [2003] and of Álvarez et al. [2003] across the same latitude. Macdonald et al. [2003] estimate two strongly diverging estimates $(0.07 \pm$ $0.91 \mathrm{Pg} \mathrm{C} \mathrm{a}^{-1}$ and $-0.47 \pm 0.99 \mathrm{Pg} \mathrm{C} \mathrm{a}^{-1}$ ) for the two separate occupation of the $24.5^{\circ}$ zonal transect, although 
Table 1. Summary of Recent Estimates of the Oceanic Uptake Rate of Anthropogenic $\mathrm{CO}_{2}$ for the Period of the $1990 \mathrm{~s}$ and Early $2000 \mathrm{~s}$

\begin{tabular}{|c|c|c|c|}
\hline Method & Estimate $\left(\mathrm{Pg} \mathrm{C} \mathrm{a}^{-1}\right)$ & Time Period & Authors \\
\hline \multicolumn{4}{|c|}{ Estimates Based on Oceanic Observations } \\
\hline Ocean Inversion (10 models) & $-2.2 \pm 0.3$ & Nominal 1995 & this study and Mikaloff Fletcher et al. [2006] \\
\hline Ocean Inversion ( 3 models) & $-1.8 \pm 0.4$ & Nominal 1990 & Gloor et al. [2003] \\
\hline Air-sea $p \mathrm{CO}_{2}$ difference (adjusted) ${ }^{\mathrm{a}}$ & $-1.9 \pm 0.7$ & Nominal $2000^{\mathrm{b}}$ & Takahashi et al. [2008] \\
\hline Air-sea $p \mathrm{CO}_{2}$ difference (adjusted) ${ }^{\mathrm{a}, \mathrm{c}}$ & $-2.0 \pm 60 \%$ & Nominal 1995 & Takahashi et al. [2002] \\
\hline \multicolumn{4}{|c|}{ Estimates Based on Atmospheric Observations } \\
\hline Atmospheric $\mathrm{O}_{2} / \mathrm{N}_{2}$ ratio & $-1.9 \pm 0.6$ & 1990-1999 & Manning and Keeling [2006] \\
\hline Atmospheric $\mathrm{O}_{2} / \mathrm{N}_{2}$ ratio & $-2.2 \pm 0.6$ & $1993-2003$ & Manning and Keeling [2006] \\
\hline Atmospheric $\mathrm{O}_{2} / \mathrm{N}_{2}$ ratio & $-1.7 \pm 0.5$ & $1993-2002$ & Bender et al. [2005] \\
\hline Atmospheric $\mathrm{CO}_{2}$ inversions (adjusted) ${ }^{\mathrm{a}}$ & $-1.8 \pm 1.0$ & $1992-1996$ & Gurney et al. [2004] \\
\hline \multicolumn{4}{|c|}{ Estimates Based on Oceanic and Atmospheric Observations } \\
\hline Air-sea ${ }^{13} \mathrm{C}$ disequilibrium & $-1.5 \pm 0.9$ & $1985-1995$ & Gruber and Keeling [2001] \\
\hline Deconvolution of atm. $\delta^{13} \mathrm{C}$ and $\mathrm{CO}_{2}$ & $-2.0 \pm 0.8$ & $1985-1995$ & Joos et al. [1999a] \\
\hline Joint atmosphere-ocean inversion & $-2.1 \pm 0.2$ & $1992-1996$ & Jacobson et al. [2007b] \\
\hline \multicolumn{4}{|c|}{ Estimates Based on Ocean Biogeochemistry Models } \\
\hline OCMIP-2 (13 models) & $-2.4 \pm 0.5$ & $1990-1999$ & Watson and Orr [2003] \\
\hline OCMIP-2 (4 "best" models) $)^{\mathrm{d}}$ & $-2.2 \pm 0.2$ & $1990-1999$ & Matsumoto et al. [2004] \\
\hline
\end{tabular}

${ }^{a}$ Adjusted by $0.45 \mathrm{Pg} \mathrm{C} \mathrm{a}^{-1}$ to account for the outgassing of natural $\mathrm{CO}_{2}$ that is driven by the carbon input by rivers.

${ }^{\mathrm{b}}$ The estimate for a nominal year of 1995 would be less than $0.1 \mathrm{Pg} \mathrm{C} \mathrm{a}^{-1}$ smaller.

${ }^{c}$ Corrected for wrong windspeeds used in published version; see http://www.ldeo.columbia.edu/res/pi/CO2/carbondioxide/pages/air_sea_flux rev1.html.

${ }^{\mathrm{d}}$ These models were selected on the basis of their ability to simulate correctly, within the uncertainty of the data, the observed oceanic inventories and regional distributions of chlorofluorocarbon and bomb radiocarbon.

with a mean that is in agreement with our estimates. Álvarez et al. [2003] compute a net contemporary southward transport of $-0.92 \pm 0.08 \mathrm{Pg} \mathrm{C} \mathrm{a}^{-1}$ across the same section, i.e., nearly three times larger than our two independent estimates. Also their transport estimate across the $4 \mathrm{x}$ line, which spans latitudes between about $40^{\circ} \mathrm{N}$ and $60^{\circ} \mathrm{N}$, is about three times larger. These large discrepancies may reflect real differences, e.g., caused by high temporal variability in transport, to which hydrographic transport estimates are fully exposed to, while the $p \mathrm{CO}_{2}$-based and the inverse transport estimates reflect more the long-term mean state. Biases are also possible, especially since hydrographic transport estimates are prone to aliasing effects due to unresolved temporal changes [see, e.g., Cunningham et al., 2007]) and undersampled mesoscale variability, [see, e.g., Wunsch, 2008].

\section{Implications and Outlook}

[63] Our estimates of the anthropogenic and contemporary air-sea $\mathrm{CO}_{2}$ fluxes and their associated ocean carbon transports have several important consequences for our understanding of the global carbon cycle and its anthropogenic perturbation. First, we are able now, with more confidence than previously possible, to quantify the global oceanic uptake of anthropogenic $\mathrm{CO}_{2}$ and its spatial distribution. This provides new and tighter constraints on the global budget of anthropogenic $\mathrm{CO}_{2}$. Second, a better understanding of today's air-sea $\mathrm{CO}_{2}$ fluxes helps to improve our ability to project the impact of future climate change on the air-sea $\mathrm{CO}_{2}$ fluxes, as well as to improve our ability to explain past changes. Third, better quantitative estimates of the contemporary air-sea $\mathrm{CO}_{2}$ fluxes and associated carbon transports can support the interpretation of atmospheric $\mathrm{CO}_{2}$ data, particularly with regard to the estimation of the net fluxes with the terrestrial biosphere. The latter aspect has been extensively discussed by Jacobson et al. [2007a] and Jacobson et al. [2007b], so we focus here just on the first two.

\subsection{Oceanic Uptake of Anthropogenic $\mathrm{CO}_{2}$}

[64] The inversion of the oceanic distribution of the reconstructed anthropogenic $\mathrm{CO}_{2}$ yields a global uptake flux of anthropogenic $\mathrm{CO}_{2}$ of $-2.2 \pm 0.3 \mathrm{Pg} \mathrm{C}^{-1}$ ( \pm 1 standard deviation) for a nominal year of 1995 [Mikaloff Fletcher et al., 2006]. This estimate compares well with the most recent set of independent estimates of the global ocean uptake of anthropogenic $\mathrm{CO}_{2}$ (Table 1), after adjustments have been applied to account for the river outgassing. To arrive at an estimate of the net uptake of anthropogenic $\mathrm{CO}_{2}$, we adopted the same global estimate of $0.45 \mathrm{Pg} \mathrm{C} \mathrm{a}^{-1}$ to adjust the net flux estimates based on $p \mathrm{CO}_{2}$ observations as well as those based on the inversion of atmospheric $\mathrm{CO}_{2}$ observations. The magnitude of this adjustment is rather uncertain, as both the actual magnitude of the river outgassing as well as the fraction of that outgassing actually included in the $p \mathrm{CO}_{2}$ climatology is not well known. This adds a substantial uncertainty to the $p \mathrm{CO}_{2}$ and atmospheric $\mathrm{CO}_{2}$-based estimates of the oceanic uptake of anthropogenic $\mathrm{CO}_{2}$.

[65] Although not significantly different from the other estimates in Table 1, our ocean inverse estimate of $-2.2 \pm$ $0.3 \mathrm{Pg} \mathrm{C} \mathrm{a}^{-1}$ stands out because of its small uncertainty. It compares well with the most recent uptake estimate based on the simultaneous measurements of $\mathrm{CO}_{2}$ and of the $\mathrm{O}_{2} / \mathrm{N}_{2}$ ratio in the atmosphere [Manning and Keeling, 2006]. This latter estimate includes a $0.5 \mathrm{Pg} \mathrm{Ca}^{-1}$ correction for the effect of the warming-induced outgassing of $\mathrm{O}_{2}$ and $\mathrm{N}_{2}$ on the atmospheric $\mathrm{O}_{2} / \mathrm{N}_{2}$ ratio, whose magnitude represents a major source of uncertainty in this method [Plattner et al., 2002; Bopp et al., 2002; Keeling and Garcia, 2002]. Our inverse estimate of the oceanic uptake of anthropogenic $\mathrm{CO}_{2}$ 
confirms also an earlier finding by Matsumoto et al. [2004] that the majority of the models that participated in OCMIP-2 tend to overestimate the oceanic uptake of anthropogenic $\mathrm{CO}_{2}$. In fact, when Matsumoto et al. [2004] selected only those 4 models that are in agreement with a number of basic oceanic chlorofluorocarbon and bomb radiocarbon constraints, they found an oceanic uptake of anthropogenic $\mathrm{CO}_{2}$ that is indistinguishable from ours (Table 1).

\subsection{Processes}

[66] An improved quantitative description of the spatial distribution of the oceanic sources and sinks of atmospheric $\mathrm{CO}_{2}$ as well as its attribution to the exchange of natural and anthropogenic $\mathrm{CO}_{2}$ helps to identify regions in the ocean that are critical in determining the past, present, and future net airsea balance of $\mathrm{CO}_{2}$. The Southern Ocean stands out with its large uptake of anthropogenic $\mathrm{CO}_{2}$ and with its substantial outgassing of natural $\mathrm{CO}_{2}$. Simulations show that this region reacts with relatively high sensitivity to climate variations over the last 50 years [Le Quéré et al., 2007; Lovenduski et al., 2007, 2008; Lenton and Matear, 2007; Verdy et al., 2007], as well as to future climate change, because of the interaction of sea-ice, upwelling, and convection with changes in heat and freshwater fluxes [Sarmiento et al., 1998]. Given the large exchange fluxes of the two $\mathrm{CO}_{2}$ components, relatively small changes in the Southern Ocean can lead to large changes in the net atmosphere-ocean balance of $\mathrm{CO}_{2}$, providing for substantial feedbacks in the climate system. Feedbacks between the physical climate system and the Southern Ocean carbon cycle have also been suggested to explain the much lower atmospheric $\mathrm{CO}_{2}$ levels during the last few periods of maximum glacial extents [Toggweiler, 1999; Sigman and Boyle, 2000; Gildor et al., 2002].

\subsection{Outlook}

[67] While our results here present a major step forward in our ability to constrain the oceanic sources and sinks of atmospheric $\mathrm{CO}_{2}$, our analysis is by design limited to the long-term mean state and, by itself, does not provide any insights on how strongly and how fast the ocean carbon cycle will respond to changes in external forcing. While there is emerging evidence that this may be occurring already [e.g., Le Quéré et al., 2007], little consensus exists what the sensitivity might be and which regions may react most strongly [e.g., Yoshikawa et al., 2008]. While we have highlighted the importance of the Southern Ocean as a region of particular relevance, it would be shortsighted to dismiss the potentially equally important contribution to change of the other oceanic regions. Identifying these regions and the underlying processes, and to quantify what we can expect to happen in the coming decades represents one of the grand challenges for ocean carbon cycle research and requires a continuing commitment to observe the time-evolving ocean carbon cycle as well as detailed modeling and process studies.

[68] Acknowledgments. We are deeply indebted to the numerous scientists and technicians involved with the sampling, processing, and quality controlling of the oceanic observations underlying this research. We are also thankful to the funding agencies, both within the U.S. as well as in many other countries who supported the collection, processing, and archiving of these data. Core financial support for this study came from the National Aeronautics and Space Administration under grant NAG5-12528 to NG and SMF, with additional support by the U.S. National Science Foundation. M. Gloor was supported by the EBI nd EEE institutes at the University of Leeds. M. Gerber, SM, FJ, and AM thank the European Commission for support through CarboOcean (511176-2) and the NOCES project (EVK2-CT-200100134). TT has been supported by NOAA grant NAO30AR4320179P27.

\section{References}

Álvarez, M., A. F. Ríos, F. F. Pérez, H. L. Bryden, and G. Rosón (2003), Transports and budgets of total inorganic carbon in the subpolar and temperate North Atlantic, Global Biogeochem. Cycles, 17(1), 1002, doi:10.1029/2002GB001881.

Aumont, O., J. C. Orr, P. Monfray, W. Ludwig, P. Amiotte-Suchet, and J.-L. Probst (2001), Riverine-driven interhemispheric transport of carbon, Global Biogeochem. Cycles, 15(2), 393-405.

Baker, D. F., et al. (2006), Transcom 3 inversion intercomparison: Impact of transport model errors on the interannual variability of regional $\mathrm{CO}_{2}$ fluxes, Global Biogeochem. Cycles, GB1002, doi:10.1029/2004GB002439.

Bender, M., D. T. Ho, M. B. Hendricks, R. Mika, M. O. Battle, P. P. Tans, T. J. Conway, B. Sturtevant, and N. Cassar (2005), Atmospheric $\mathrm{O}_{2} / \mathrm{N}_{2}$ changes, 1993-2002: Implications for the partitioning of fossil fuel $\mathrm{CO}_{2}$ sequestration, Global Biogeochem. Cycles, 19, GB4017, doi:10.1029/ 2004GB002410.

Bolin, B., and C. D. Keeling (1963), Large-scale atmospheric mixing as deduced from the seasonal and meridional variations of carbon dioxide, J. Geophys. Res., 68, 3899-3920.

Bopp, L., C. LeQuéré, M. Heimann, A. Manning, and P. Monfray (2002), Climate-induced oceanic oxygen fluxes: Implications for the contemporary carbon budget, Global Biogeochem. Cycles, 16(2), 1022, doi:10.1029/2001GB001445

Brewer, P. G., C. Goyet, and D. Dyrssen (1989), Carbon dioxide transport by ocean currents at $25^{\circ} \mathrm{N}$ latitude in the Atlantic Ocean, Science, 246, $477-479$.

Caldeira, K., and P. B. Duffy (2000), The role of the Southern Ocean in uptake and storage of anthropogenic carbon dioxide, Science, 287, 620-622.

Cox, P. M., R. A. Betts, C. D. Jones, S. A. Spall, and I. J. Totterdell (2000), Acceleration of global warming due to carbon-cycle feedbacks in a coupled climate model, Nature, 408, 184-187.

Cunningham, S., et al. (2007), Temporal variability of the Atlantic meridional overturning circulation at $26.5^{\circ} \mathrm{N}$, Science, 317(5840), 935-938, doi:10.1126/science.1141,304.

Denman, K. L., et al. (2007), Couplings between changes in the climate system and biogeochemistry, in Climate Change 2007: The Physical Science Basis. Contribution of Working Group I to the Fourth Assessment Report of the Intergovernmental Panel on Climate Change, edited by S. Solomon et al, chap. 7, pp. 501-587, Cambridge Univ. Press, Cambridge, UK.

Denning, A. S., I. Y. Fung, and D. Randall (1995), Latitudinal gradient of atmospheric $\mathrm{CO}_{2}$ due to seasonal exchange with land biota, Nature, 376, $240-243$.

Doney, S. C., and M. W. Hecht (2002), Antarctic bottom water formation and deep water chlorofluorocarbon distributions in a global climate model, J. Phys. Oceanogr., 32, 1642-1666.

Doney, S. C., et al. (2004), Evaluating global ocean carbon models: The importance of realistic physics, Global Biogeochem. Cycles, 18, GB3017, doi:10.1029/2003GB002150.

Dutay, J.-C., et al. (2002), Evaluation of ocean model ventilation with CFC-11: Comparison of 13 global ocean models, Ocean Modell., 4, 89-120.

Enting, I. G., and J. V. Mansbridge (1989), Latitudinal distribution of sources and sinks of atmospheric $\mathrm{CO}_{2}$ : Direct inversion of filtered data, Tellus, Ser. B., 41, 111-126.

Feely, R. A., R. Wanninkhof, T. Takahashi, and P. Tans (1999), Influence of El Niño on the equatorial Pacific contribution to atmospheric $\mathrm{CO}_{2}$ accumulation, Nature, 398, 597-601.

Feely, R., T. Takahashi, R. Wanninkhof, M. J. McPhaden, C. E. Cosca, S. C. Sutherland, and M. Carr (2006), Decadal variability of the air-sea $\mathrm{CO}_{2}$ fluxes in the equatorial Pacific Ocean, J. Geophys. Res., 111, C08S90, 10.1029/2005JC003129.

Friedlingstein, P., et al. (2006), Climate-carbon cycle feedback analysis results from the C4MIP model intercomparison., J. Clim., 19, 3337-3353.

Fung, I. Y., S. C. Doney, K. Lindsay, and J. John (2005), Evolution of carbon sinks in a changing climate, Proc. Natl. Acad. Sci., 202, 11201-11206, doi:10.1073/pnas.0504949,102.

Gammon, R. H., J. Cline, and D. Wisegarver (1982), Chlorofluoromethanes in the northeast Pacific Ocean: Measured vertical distributions and application as transient tracers of upper ocean mixing, J. Geophys. Res., 87(C12), $9441-9454$ 
Gildor, H., E. Tziperman, and J. R. Toggweiler (2002), Sea ice switch mechanism and glacial-interglacial $\mathrm{CO}_{2}$ variations, Global Biogeochem. Cycles, 16(3), 1032, doi:10.1029/2001GB001446.

Gloor, M., S.-M. Fan, S. W. Pacala, and J. L. Sarmiento (2000), Optimal sampling of the atmosphere for purpose of inverse modelling: A model study, Global Biogeochem. Cycles, 14(1), 407-428.

Gloor, M., N. Gruber, T. M. C. Hughes, and J. L. Sarmiento (2001), An inverse modeling method for estimation of net air-sea fluxes from bulk data: Methodology and application to the heat cycle, Global Biogeochem. Cycles, 15, 767-782, doi:10.1029/2000GB001301.

Gloor, M., N. Gruber, J. L. Sarmiento, C. L. Sabine, R. A. Feely, and C. Roedenbeck (2003), A first estimate of present and pre-industrial airsea $\mathrm{CO}_{2}$ fluxes patterns based on ocean interior carbon measurements and models, Geophys. Res. Lett., 30(1), 1010, 10.1029/2002GL015594.

Gnanadesikan, A., N. Gruber, R. D. Slater, and J. L. Sarmiento (2002), Oceanic vertical exchange and new production: A comparison between model results and observations, Deep Sea Res. II, 49, 363-401.

Gnanadesikan, A., J. P. Dunne, R. M. Key, K. Matsumoto, J. L. Sarmiento, R. D. Slater, and P. S. Swathi (2004), Oceanic ventilation and biogeochemical cycling: Understanding the physical mechanisms that produce realistic distributions of tracers and productivity, Global Biogeochem. Cycles, 18, GB4010, doi:10.1029/2003GB002097.

Gruber, N. (1998), Anthropogenic $\mathrm{CO}_{2}$ in the Atlantic Ocean, Global Biogeochem. Cycles, 12(1), 165-191, doi:10.1029/97GB03,658.

Gruber, N., and C. D. Keeling (2001), An improved estimate of the isotopic air-sea disequilibrium of $\mathrm{CO}_{2}$ : Implications for the oceanic uptake of anthropogenic $\mathrm{CO}_{2}$, Geophys. Res. Lett., 28(3), 555-558, doi:10.1029/ 2000GL011853.

Gruber, N., and J. L. Sarmiento (2002), Large-scale biogeochemical/physical interactions in elemental cycles, The Sea: Biological-Physical Interactions in the Oceans, edited by A. R. Robinson, J. J. McCarthy, and B. J. Rothschild, vol. 12, pp. 337-399, John Wiley, New York.

Gruber, N., J. L. Sarmiento, and T. F. Stocker (1996), An improved method for detecting anthropogenic $\mathrm{CO}_{2}$ in the oceans, Global Biogeochem. Cycles, 10(4), 809-837, doi:10.1029/96GB01,608.

Gruber, N., E. Gloor, T. M. C. Hughes, and J. L. Sarmiento (2001), Air-sea flux of oxygen estimated from bulk data: Implications for the marine and atmospheric oxygen cycle, Global Biogeochem. Cycles, 15, 783-803, doi:10.1029/2000GB001302.

Gruber, N., N. Bates, and C. D. Keeling (2002), Interannual variability in the North Atlantic carbon sink, Science, 298, 2374-2378.

Gruber, N., P. Friedlingstein, C. B. Field, R. Valentini, M. Heimann, J. E. Richey, P. Romero-Lankao, D. Schulze, and C. Chen (2004), The vulnerability of the carbon cycle in the 21st century: An assessment of carbon-climate-human interactions, in The Global Carbon Cycle: Integrating Humans, Climate, and the Natural World, edited by C. B. Field and M. R. Raupach, chap. 2, pp. 45-76, Island Press, Washington, D.C.

Gurney, K. R., et al. (2002), Towards robust regional estimates of $\mathrm{CO}_{2}$ sources and sinks using atmospheric transport models, Nature, 415, 626-630.

Gurney, K. R., et al. (2003), TransCom $3 \mathrm{CO}_{2}$ inversion intercomparison: 1. Annual mean control results and sensitivity to transport and prior flux information, Tellus, Ser. B., 55, 555-579.

Gurney, K. R., et al. (2004), Transcom 3 inversion intercomparison: Model mean results for the estimation of seasonal carbon sources and sinks, Global Biogeochem. Cycles, 18, GB1010, doi:10.1029/2003GB002111.

Gurney, K. R., D. Baker, P. Rayner, and S. Denning (2008), Interannual variations in continental-scale net carbon exchange and sensitivity to observing networks estimated from atmospheric $\mathrm{CO}_{2}$ inversions for the period 1980 to 2005, Global Biogeochem. Cycles, 22, GB3025, doi:10.1029/2007GB003082.

Ho, D. T., C. S. Law, M. J. Smith, P. Schlosser, M. Harvey, and P. Hill (2006), Measurements of air-sea gas exchange at high wind speeds in the Southern Ocean: Implications for global parameterizations, Geophys. Res. Lett., 33, L16611, doi:10.1029/2006GL026817.

Holfort, J., K. M. Johnson, B. Siedler, and D. W. R. Wallace (1998), Meridional transport of dissolved inorganic carbon in the South Atlantic Ocean, Global Biogeochem. Cycles, 12(3), 479-499.

Houghton, R. A. (2003), Revised estimates of the annual net flux of carbon to the atmosphere from changes in land use and land management 1850 2000, Tellus, Ser. B., 55(2), 378-390.

Jacobson, A. R., S. E. Mikaloff Fletcher, N. Gruber, J. L. Sarmiento, and M. Gloor (2007a), A joint atmosphere-ocean inversion for surface fluxes of carbon dioxide: 1. Methods and global-scale fluxes, Global Biogeochem. Cycles, 21, GB1019, doi:10.1029/2005GB002556.

Jacobson, A. R., S. E. Mikaloff Fletcher, N. Gruber, J. L. Sarmiento, and M. Gloor (2007b), A joint atmosphere-ocean inversion for surface fluxes of carbon dioxide. 2: Regional results, Global Biogeochem. Cycles, 21, GB1020, doi:10.1029/2006GB002703.

Jones, P. D., and A. Moberg (2003), Hemispheric and large-scale surface air temperature variations: An extensive revision and an update to 2001 , J. Clim., 16, 206-223

Joos, F., R. Meyer, M. Bruno, and M. Leuenberger (1999a), The variability in the carbon sinks as reconstructed for the last 1000 years, Geophys. Res. Lett., 26, 1437-1441.

Joos, F., G.-K. Plattner, T. F. Stocker, O. Marchal, and A. Schmittner (1999b), Global warming and marine carbon cycle feedbacks on future atmospheric $\mathrm{CO}_{2}$, Science, 284, 464-467.

Keeling, C. D., S. C. Piper, and M. Heimann (1989), A three dimensional model of atmospheric $\mathrm{CO}_{2}$ transport based on observed winds: 4. Mean annual gradients and interannual variations, in Aspects of Climate Variability in the Pacific and the Western Americas, edited by D. H. Peterson, Geophys. Monogr. Ser., vol. 55, pp. 305-363, AGU, Washington, D.C. Keeling, C., H. Brix, and N. Gruber (2004), Seasonal and long-term dynamics of the upper ocean carbon cycle at station ALOHA near Hawaii, Global Biogeochem. Cycles, 18, GB4006, doi:10.1029/2004GB002227.

Keeling, R. F. (2005), Comment on "The oceanic sink for anthropogenic $\mathrm{CO}_{2}$ " by Sabine et al., Science, 308, 1743, www.sciencemag.org/cgi/ content/full/308/5729/1743c.

Keeling, R. F., and H. E. Garcia (2002), The change in oceanic $\mathrm{O}_{2}$ inventory associated with recent global warming, Proce. Natl. Acad. Sci., 99(12), $7848-7853$

Keeling, R. F., and T.-H. Peng (1995), Transport of heat, $\mathrm{CO}_{2}$ and $\mathrm{O}_{2}$ by the Atlantic's thermohaline circulation, Philos. Trans. R. Soc. London, Ser. B, $348,133-142$.

Key, R. M., et al. (2004), A global ocean carbon climatology: Results from Global Data Analysis Project (GLODAP), Global Biogeochem. Cycles, 18, GB4031, doi:10.1029/2004GB002247

Krakauer, N. Y., J. T. Randerson, F. W. Primeau, N. Gruber, and D. Menemenlis (2006), Carbon isotope evidence for the latitudinal distribution and wind speed dependence of the air-sea gas transfer velocity, Tellus, Ser. B., 58, 390-417, doi:10.1111/j.1600-0889.2006.00223.x.

Lachkar, Z., J. C. Orr, J.-C. Dutay, and P. Delecluse (2007), Effects of mesoscale eddies on global distributions of CFC-11, $\mathrm{CO}_{2}$ and $\Delta^{14} \mathrm{C}$, Ocean Sci., 3, 461-482, www.ocean-sci.net/3/461/2007/.

Le Quéré, C., J. C. Orr, P. Monfray, O. Aumont, and G. Madec (2000), Interannual variability of the oceanic sink of $\mathrm{CO}_{2}$ from 1979 through 1997, Global Biogeochem. Cycles, 14, 1247-1265.

Le Quéré, C., et al. (2007), Saturation of the Southern Ocean $\mathrm{CO}_{2}$ sink due to recent climate change, Science, 316, 1735-1738.

Lefèvre, N., A. J. Watson, A. Olsen, A. F. Rios, F. F. Perez, and T. Johannessen (2004), A decrease in the sink for atmospheric $\mathrm{CO}_{2}$ in the North Atlantic, Geophys. Res. Lett., 31, L07306, doi:10.1029/2003GL018957.

Lenton, A., and R. J. Matear (2007), Role of the Southern Annular Mode (SAM) in Southern Ocean $\mathrm{CO}_{2}$ uptake, Global Biogeochem. Cycles, 21, GB2016, doi:10.1029/2006GB002714.

Lovenduski, N. S., N. Gruber, S. C. Doney, and I. D. Lima (2007), Enhanced $\mathrm{CO}_{2}$ outgassing in the Southern Ocean from a positive phase of the Southern Annular Mode, Global Biogeochem. Cycles, 21, GB2026, doi:10.1029/ 2006GB002900

Lovenduski, N. S., N. Gruber, and S. C. Doney (2008), Toward a mechanistic understanding of the decadal trends in the Southern Ocean carbon sink, Global Biogeochem. Cycles, 22, GB3016, doi:10.1029/2007GB003139.

Ludwig, W., J.-L. Probst, and S. Kempe (1996), Predicting the oceanic input of organic carbon by continental erosion, Global Biogeochem. Cycles, 10(1), 23-41.

Macdonald, A. M., M. O. Baringer, R. Wanninkhof, K. Lee, and D. W. R. Wallace (2003), A 1998-1992 comparison of inorganic carbon and its transport across $24.5^{\circ} \mathrm{n}$ in the Atlantic, Deep Sea Res. II, 50(22-26), 3041-3064, doi: 10.1016/j.dsr2.2003.07.009.

Manning, A. C., and R. F. Keeling (2006), Global oceanic and land biotic carbon sinks from the Scripps atmospheric oxygen flask sampling network, Tellus, Ser. B., 58, 95-116.

Marland, G., T. A. Boden, and R. J. Andres (2006), Global, regional and national fossil fuel $\mathrm{CO}_{2}$ emissions, in Trends: A Compendium of Data on Global Change, Carbon Dioxide Inf. Anal. Cent. Oak Ridge Natl. Lab., U.S. Dept. of Energy, Oak Ridge, Tenn., U.S.A.

Matear, R. J., and A. C. Hirst (1999), Climate change feedback on the future oceanic $\mathrm{CO}_{2}$ uptake, Tellus, Ser. B., 51, 722-733.

Matsumoto, K., and N. Gruber (2005), How accurate is the estimation of anthropogenic carbon in the ocean?: An evaluation of the $\Delta \mathrm{C}^{*}$ method, Global Biogeochem. Cycles, 19, GB3014, doi:10.1029/2004GB002397.

Matsumoto, K., et al. (2004), Evaluation of ocean carbon cycle models with data-based metrics, Geophys. Res. Lett., 31, L07303, doi:10.1029/ 2003GL018970. 
McKinley, G. A., C. Rödenbeck, M. Gloor, S. Houweling, and M. Heimann (2004), Pacific dominance to global air-sea $\mathrm{CO}_{2}$ flux variability: A novel atmospheric inversion agrees with ocean models, Geophys. Res. Lett., 31, L22308, doi:10.1029/2004GL021069.

McKinley, G. A., et al. (2006), North Pacific carbon cycle response to climate variability on seasonal to decadal timescales, J. Geophys. Res., 111, C07S06, doi:10.1029/2005JC003173.

McNeil, B. I., N. Metzl, R. M. Key, R. J. Matear, and A. Corbiere (2007), An empirical estimate of the Southern Ocean air-sea $\mathrm{CO}_{2}$ flux, Global Biogeochem. Cycles, 21, GB3011, doi:10.1029/2007GB002991.

Mikaloff Fletcher, S. E., et al. (2006), Inverse estimates of anthropogenic $\mathrm{CO}_{2}$ uptake, transport, and storage by the ocean, Global Biogeochem. Cycles, 20, GB2002, doi:10.1029/2005GB002530.

Mikaloff Fletcher, S. E., et al. (2007), Inverse estimates of the oceanic sources and sinks of natural $\mathrm{CO}_{2}$ and the implied oceanic transport, Global Biogeochem. Cycles, 21, GB1010, doi:10.1029/2006GB002751.

Müller, S. A., F. Joos, N. R. Edwards, and T. F. Stocker (2008), Modeled natural and excess radiocarbon: Sensitivies to the gas exchange formulation and ocean transport strength, Global Biogeochem. Cycles, 22 , GB3011, doi:10.1029/2007GB003065.

Murnane, R. J., J. L. Sarmiento, and C. LeQuéré (1999), The spatial distribution of air-sea fluxes and the interhemispheric transport of carbon by the oceans, Global Biogeochem. Cycles, 13, 287-305.

Naegler, T., P. Ciais, K. B. Rodgers, and I. Levin (2006), Excess radiocarbon constraints on air-sea gas exchange and the uptake of $\mathrm{CO}_{2}$ by the oceans, Geophys. Res. Lett., L11802, doi:10.1029/2005GL025408.

Najjar, R. G., et al. (2007), Impact of circulation on export production, dissolved organic matter and dissolved oxygen in the ocean: Results from phase ii of the ocean carbon-cycle model intercomparison project (ocmip-2), Global Biogeochem. Cycles, 21, GB3007, doi:10.1029/ 2006 GB002857.

Nightingale, P. D., G. Malin, C. S. Law, A. J. Watson, P. S. Liss, M. I. Liddicoat, J. Boutin, and R. C. Upstill-Goddard (2000), In situ evaluation of air-sea gas exchange parameterizations using novel conservative and volatile tracers, Global Biogeochem. Cycles, 14(1), 373-387.

Orr, J. C., et al. (2001), Estimates of anthropogenic carbon uptake from four three-dimensional global ocean models, Global Biogeochem. Cycles, $15(1), 43-60$.

Patra, P. K., et al. (2006), Sensitivity of inverse estimation of annual mean $\mathrm{CO}_{2}$ sources and sinks to ocean-only sites versus all-sites observational networks, Geophys. Res. Lett., 33, L05814, doi:10.1029/2005GL025403.

Peacock, S. (2004), Debate over the ocean bomb radiocarbon sink: Closing the gap, Global Biogeochem. Cycles, 18, GB2022, 10.1029/ 2003GB002211.

Plattner, G.-K., F. Joos, T. F. Stocker, and O. Marchal (2001), Feedback mechanisms and sensitivities of ocean carbon uptake under global warming, Tellus, Ser. B., 53, 564-592.

Plattner, G.-K., F. Joos, and T.F. Stocker (2002), Revision of the global carbon budget due to changing air-sea oxygen fluxes, Global Biogeochem. Cycles, 16(4), 1096, doi:10.1029/2001GB001746.

Roy, R., P. Rayner, R. Matear, and R. Francey (2003), Southern hemisphere ocean $\mathrm{CO}_{2}$ uptake: reconciling atmospheric and oceanic estimates, Tellus, Ser. B., 55(2), 701-710.

Sabine, C. L., and N. Gruber (2005), Response to comment on "The oceanic sink for anthropogenic $\mathrm{CO}_{2}$ ” by R.F. Keeling, Science, 308(5729), 1740, doi:10.1126/science.308.5729.1740a.

Sabine, C. L., et al. (2004), The oceanic sink for anthropogenic $\mathrm{CO}_{2}$, Science, $305,367-371$

Sarmiento, J. L., and N. Gruber (2002), Anthropogenic carbon sinks, Phys Today, 55, 30-36.

Sarmiento, J. L., and E. T. Sundquist (1992), Revised budget for the oceanic uptake of anthropogenic carbon dioxide, Nature, 356, 589-593.

Sarmiento, J. L., J. C. Orr, and U. Siegenthaler (1992), A perturbation simulation of $\mathrm{CO}_{2}$ uptake in an ocean general circulation model, J. Geophys. Res., 97(C3), 3621-3645.

Sarmiento, J. L., T. M. C. Hughes, R. J. Stouffer, and S. Manabe (1998), Simulated response of the ocean carbon cycle to anthropogenic climate warming, Nature, 393, 245-249.

Sarmiento, J. L., P. Monfray, E. Maier-Reimer, O. Aumont, R. Murnane, and J. Orr (2000), Air-sea fluxes and carbon transport: A comparison of three ocean general circulation models, Global Biogeochem. Cycles, 14, $1267-1281$

Schmitz, W. J. J. (1995), On the interbasin-scale thermohaline circulation, Rev. Geophys., 33(2), 151-173.

Schuster, U., and A. J. Watson (2007), A variable and decreasing sink for atmospheric $\mathrm{CO}_{2}$ in the North Atlantic, J. Geophys. Res., 112, C11006, doi:10.1029/2006JC003941.
Sigman, D. M., and E. A. Boyle (2000), Glacial/interglacial variations in carbon dioxide: Searching for a cause, Nature, 407, 859-869.

Sweeney, C., E. Gloor, A.R. Jacobson, R.M. Key, G. McKinley, J.L. Sarmiento, and R. Wanninkhof (2007), Constraining global air-sea gas exchange for $\mathrm{CO}_{2}$ with recent bomb ${ }^{14} \mathrm{C}$ measurements, Global Biogeochem. Cycles, 21 , GB2015, doi:10.1029/2006GB002784.

Takahashi, T., R. A. Feely, R. Weiss, R. H. Wanninkhof, D. W. Chipman, S. C. Sutherland, and T. T. Takahashi (1997), Global air-sea flux of $\mathrm{CO}_{2}$ An estimate based on measurements of sea-air $\mathrm{pCO}_{2}$ difference, Proc. Natl. Acad. Sci., 94, 8292-8299.

Takahashi, T., R. H. Wanninkhof, R. A. Feely, R. F. Weiss, D. W. Chipman, N. Bates, J. Olafsson, C. Sabine, and S. C. Sutherland (1999), Net sea-air $\mathrm{CO}_{2}$ flux over the global oceans: An improved estimate based on the seaair $\mathrm{pCO}_{2}$ difference, in Second International Symposium, $\mathrm{CO}_{2}$ in the Oceans, Extended Abstracts, pp. 9-15, Center Global Env. Res, Tsukuba, Japan.

Takahashi, T., et al. (2002), Global sea-air $\mathrm{CO}_{2}$ flux based on climatologica surface ocean $p \mathrm{CO}_{2}$, and seasonal biological and temperature effects, Deep Sea Res. II, 49(9-10), 1601-1622.

Takahashi, T., S. C. Sutherland, R. A. Feely, and C. E. Cosca (2003), Decadal variation of the surface water $p \mathrm{CO}_{2}$ in the western and eastern equatorial Pacific, Science, 302, 852-856.

Takahashi, T., S. C. Sutherland, R. A. Feely, and R. Wanninkhof (2006), Decadal change of the surface water $p \mathrm{CO}_{2}$ in the North Pacific: A synthesis of 35 years of observations, J. Geophys. Res., 111, C07S05, doi:10.1029/2005JC003074

Takahashi, T., et al. (2008), Climatological mean and decadal changes in surface ocean $p \mathrm{CO}_{2}$, and net sea-air $\mathrm{CO}_{2}$ flux over the global oceans, Deep Sea Res. II, doi:10.1016/j.dsr2.2008.12.009, in press.

Tanhua, T., A. Körtzinger, K. Friis, D. W. Waugh, and D. W. R. Wallace (2007), An estimate of anthropogenic $\mathrm{CO}_{2}$ inventory from decadal changes in oceanic carbon content, Proce. Natl. Acad. Sci., 104(9), 3037-3042, doi:10.1073pnas.0606574104

Tans, P. P., I. Y. Fung, and T. Takahashi (1990), Observational constraints on the global atmospheric $\mathrm{CO}_{2}$ budget, Science, 247, 1431-1438.

Taylor, K. E. (2001), Summarizing multiple aspects of model performance in a single diagram, J. Geophys. Res., 106(D7), 7183-7192.

Toggweiler, J. R. (1999), Variations of atmospheric $\mathrm{CO}_{2}$ driven by ventilation of the ocean's deepest water, Paleoceanography, 14(5), 571-588.

Verdy, A., S. Dutkiewicz, M. J. Follows, J. Marshall, and A. Czaja (2007), Carbon dioxide and oxygen fluxes in the Southern Ocean: Mechanisms of interannual variability, Global Biogeochem. Cycles, 21, GB2020, doi:10.1029/2006GB002916.

Wanninkhof, R. (1992), Relationship between wind speed and gas exchange over the ocean, J. Geophys. Res., 97(C5), 7373-7382.

Wanninkhof, R., and W. R. McGillis (1999), A cubic relationship between air-sea $\mathrm{CO}_{2}$ exchange and wind speed, Geophys. Res. Lett., 26(13), $1889-1892$

Watson, A. J., and J. C. Orr (2003), Carbon dioxide fluxes in the global ocean, in Ocean Biogeochemistry: A JGOFS Synthesis, edited by M. Fasham et al., chap. 5, pp. 123-141, Springer, Berlin

Wetzel, P., A. Winguth, and E. Maier-Reimer (2005), Sea-to-air $\mathrm{CO}_{2}$ flux from 1948 to 2003: A model study, Global Biogeochem. Cycles, 19(2), GB2005, doi:10.1029/2004GB002339.

Wunsch, C. (2008), Mass and volume transport variability in an eddy-filled ocean, Nat. Geosci., 1(3), 165.

Yoshikawa, C., M. Kawamiya, T. Kato, Y. Yamanaka, and T. Matsuno (2008), Geographical distribution of the feedback between future climate change and the carbon cycle, J. Geophys. Res., 113, G03002, 10.1029/ 2007JG000570.

S. C. Doney, Marine Chemistry and Geochemistry, MS 25, Woods Hole Oceanographic Institution, 360 Woods Hole Road, Woods Hole, MA 02543-1543, USA. (sdoney@whoi.edu)

S. Dutkiewicz and M. J. Follows, Department of Earth, Atmosphere, and Planetary Sciences, Massachusetts Institute of Technology, 54-1412, 77 Massachusetts Avenue, Cambridge, MA 02139, USA. (stephd@ocean.mit. edu; mick@ocean.mit.edu)

M. Gerber and F. Joos, Climate and Environmental Physics, Physics Institute, University of Bern, Sidlerstrasse 5, CH-3012 Bern, Switzerland. (mgerber@climate.unibe.ch; joos@climate.unibe.ch)

M. Gloor, School of Geography, University of Leeds, Leeds LS2 9JT, UK. (e.gloor@leeds.ac.uk)

N. Gruber, Environmental Physics, Institute of Biogeochemistry and Pollutant Dynamics, ETH Zürich, CHN E31.2, Universitätstrasse 16, CH-8092 Zürich, Switzerland. (nicolas.gruber@env.ethz.ch) 
A. R. Jacobson, NOAA Earth System Research Laboratory, Global Monitoring Division, Boulder, CO 80305, USA. (andy.jacobson@noaa.gov)

K. Lindsay, Climate and Global Dynamics, National Center for Atmospheric Research, P.O. Box 3000, Boulder, CO 80307, USA. (klindsay@ucar.edu)

D. Menemenlis, Jet Propulsion Laboratory, MS 300-323, 4800 Oak Grove Drive, Pasadena, CA 91109, USA. (menemenlis@jpl.nasa.gov)

S. E. Mikaloff Fletcher and J. L. Sarmiento, Program in Atmospheric and Oceanic Sciences, Princeton University, PO Box CN710, Princeton, NJ 08544-0710, USA. (mikaloff@princeton.edu; jls@princeton.edu)
A. Mouchet, Astrophysics and Geophysics Institute, University of Liege, Allée du 6 Août, 17 Bt. B5c, B-4000 Liege, Belgium. (a.mouchet@ulg.ac.be) S. Müller, Department of Earth and Environmental Sciences, Open University, Walton Hall, Milton Keynes MK7 6AA, UK. (s.a.mueller@ open.ac.uk)

T. Takahashi, Lamont-Doherty Earth Observatory of Columbia University, Palisades, NY 10964-8000, USA. (taka@ldeo.columbia.edu) 